Supporting Information

\title{
Circularly Polarized Phosphorescent Electroluminescence with a High Dissymmetry Factor from PHOLEDs Based on a Platinahelicene
}

Jochen R. Brandt, ${ }^{\dagger}$ Xuhua Wang, ${ }^{\S_{\|}}$Ying Yang, ${ }^{\S}$ Alasdair J. Campbell, ${ }^{\S} \|$ and Matthew J. Fuchter $^{* \dagger} \|$

†Department of Chemistry, Imperial College London, South Kensington Campus, London SW7 2AZ, UK §Department of Physics, Imperial College London, South Kensington campus, London, SW7 2AZ, UK

॥Centre for Plastic Electronics, Imperial College London, South Kensington campus, London, SW7 2AZ, UK

Email: m.fuchter@imperial.ac.uk 


\section{Table of Contents}

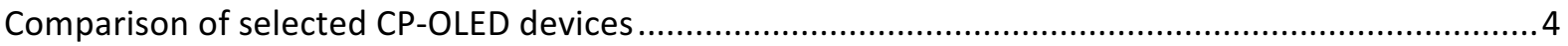

Table S1 Comparison of device characteristics for different approaches to CP-OLEDs. ................4

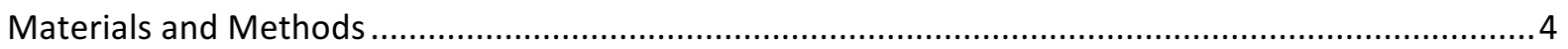

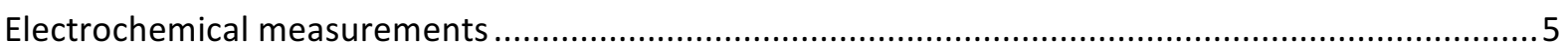

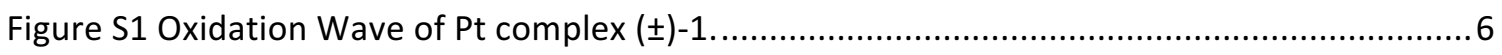

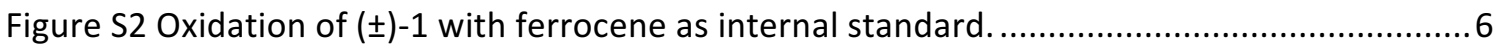

Figure S3 Cyclic Voltammetry of $( \pm)-1$ with ferrocene as internal standard. ...............................6

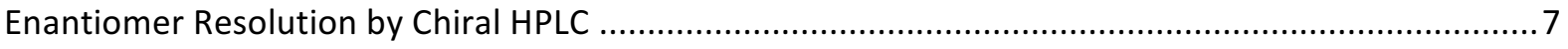

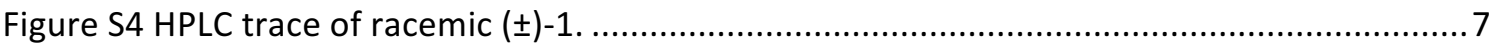

Figure S5 HPLC trace of first-eluting (+)-1 after chiral resolution. ........................................... 8

FigureS6 HPLC trace of second-eluting (-)-1 after chiral resolution. .........................................

Sign convention of left- and right-handed circularly polarized light ...............................................

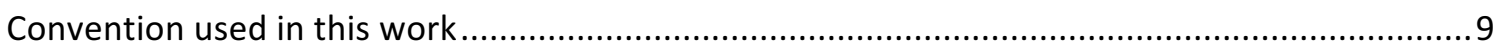

Experimental convention used in this work to measure circularly polarized photoluminescence

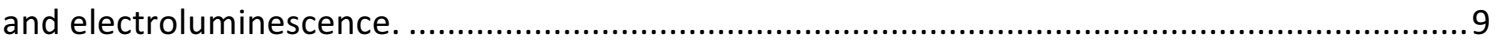

Experimental convention used in circular dichroism measurements ....................................... 10

Discussion of Dissymmetry Factor and Anti-Glare Filter ................................................................ 10

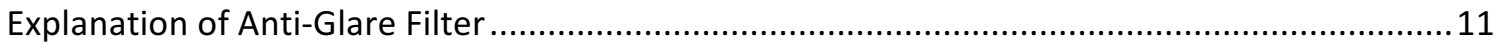

Figure S7 Circular polarizer reduces glare by filtering out ambient light. .................................. 11

Figure S8 Effect of circular polarizer on conventional OLED display brightness. .......................... 12

Figure S9 CP-OLEDs achieve higher brightness compared to non-polarized emission. ................12

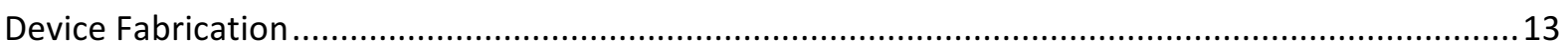

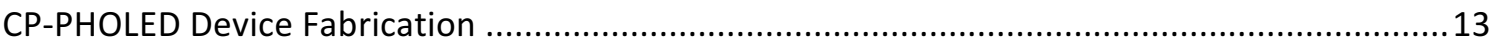

Photophysical and morphology characterization.................................................................... 13

Thin Film Circular Dichroism spectra characterization ............................................................ 13

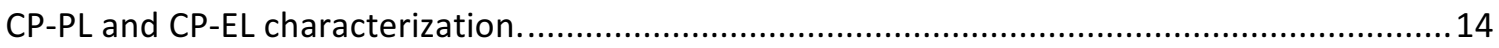

Commission internationale de l'éclairage (CIE) coordinates ................................................... 14

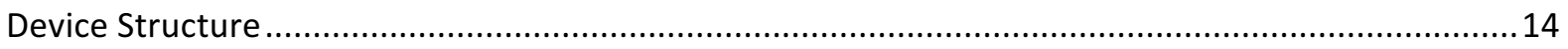

Figure S10 Photograph of a PHOLED (15 wt\% (+)-1 in PVK:OXD-7 1:1 matrix) in operation, no

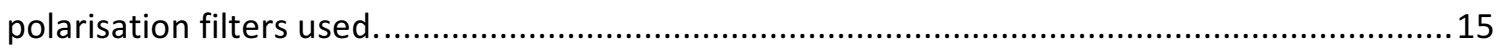

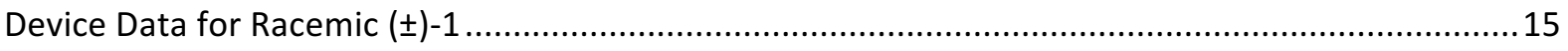

Figure S11 J-V-L graph of OLED devices with 12 wt\% racemic ( \pm )-1 in PVK:OXD-7 matrices. ...... 15

Figure S12 Efficiency of OLED devices with 12 wt\% racemic ( \pm )-1 in PVK:OXD-7 matrices..........15 
Figure S13 Normalized EL spectra of OLED devices with 12 wt\% racemic $( \pm)-1$ in PVK:OXD-7

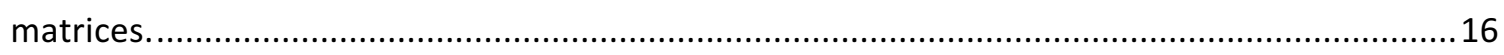

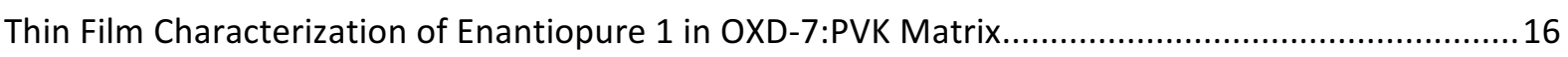

Figure S16 Optical and AF microscopy images of 15 wt\% (-)-1 in OXD-7:PVK 50:50 film, $R_{q}=$

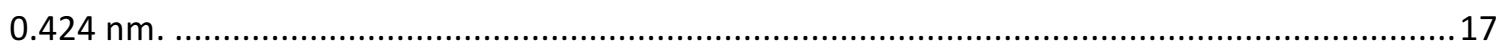

Figure S17 Optical and AF microscopy images of 15 wt\% (+)-1 in OXD-7:PVK 50:50 film, $R_{q}=$

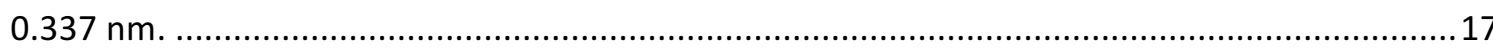

Device Data for Enantiopure 1, Influence of Layer Composition ............................................. 18

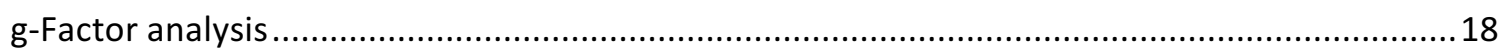

Figure S19 J-V-L graph of OLED device with 15 wt\% (-)-1 in OXD-7:PVK 50:50 matrix..............18

Figure S20 Efficiency of OLED device with 15 wt\% (-)-1 in OXD-7:PVK 50:50 matrix. ...............19

Figure S21 J-V-L graph of OLED device with 15 wt\% (-)-1 in OXD-7:PVK 70:30 matrix from matrix

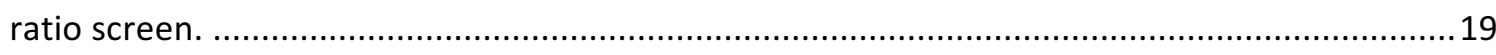

Figure S22 Efficiency of OLED device with 15 wt\% (-)-1 in OXD-7:PVK 70:30 matrix from matrix

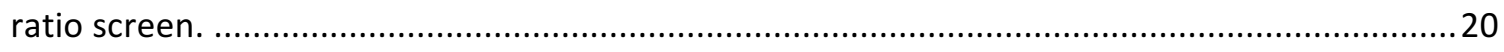

Figure S23 Current efficiency dependent on OXD-7:PVK ratio (OXD-7+PVK $=10 \mathrm{mg} / \mathrm{mL}$ in chloroform); 15 wt\% (-)-1................................................................................ 20

Figure S24 g-Factor dependent on OXD-7:PVK ratio (OXD-7+PVK = $10 \mathrm{mg} / \mathrm{mL}$ in chloroform);

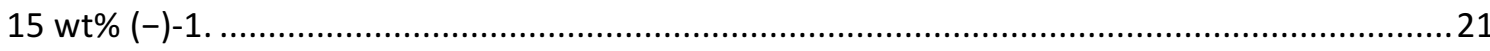

Figure S25 Dependence of g-factor and power efficiency on Ca cathode thickness for 5 wt\% (-)1, OXD-7:PVK 70:30.

Figure S26 Dependence of g-factor and power efficiency on Al cathode thickness for 5 wt\% (-)-

1, OXD-7:PVK 70:30....... 22

Figure S27 J-V-L graph of OLED device with 15 wt\% (+)-1 in OXD-7:PVK 70:30 matrix..............22

Figure S28 Efficiency of OLED device with 15 wt\% (+)-1 in OXD-7:PVK 70:30 matrix. ...............23

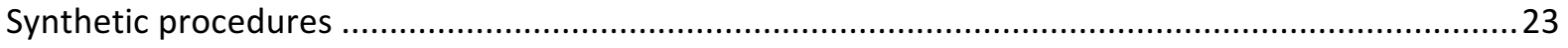

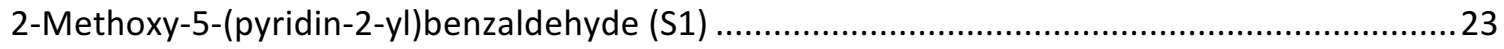

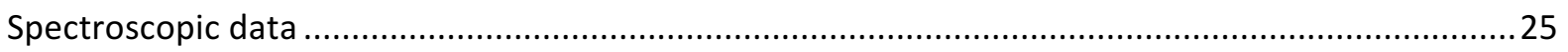

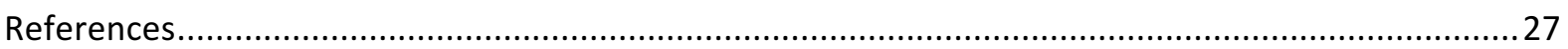




\section{Comparison of selected CP-OLED devices}

For a list of chiroptical properties of state-of-the-art conjugated polymer thin films, please see the SI of ref ${ }^{1}$.

Table S1 Comparison of device characteristics for different approaches to CP-OLEDs.

\begin{tabular}{|c|c|c|c|c|c|c|c|c|c|}
\hline Material & Processing & $\begin{array}{l}\text { Phospho- } \\
\text { rescence }\end{array}$ & Colour & $\begin{array}{l}\lambda_{\mathrm{em}} \\
(\mathrm{nm})\end{array}$ & $\left|\mathrm{g}_{\mathrm{EL}}\right|$ & $\begin{array}{l}L_{V \max } \\
\mathrm{cd} / \mathrm{m}^{2}\end{array}$ & $\mathrm{~cd} / \mathrm{A}$ & $\mathrm{Im} / \mathrm{W}$ & Ref \\
\hline $\begin{array}{l}\text { PFO with } \\
\text { chiral } \\
\text { sidechains }\end{array}$ & $\begin{array}{l}\text { solution } \\
\text { processed } \\
\text { single layer / } \\
\text { on LC } \\
\text { alignment } \\
\text { layer }\end{array}$ & No & $\begin{array}{l}\text { violet } \\
\text { /blue }\end{array}$ & $\begin{array}{l}420- \\
550\end{array}$ & 0.35 & $n / a$ & 0.94 & $n / a$ & 2 \\
\hline $\begin{array}{l}\text { PFO } \\
\text { copolymer } \\
\text { with 7\% } \\
\text { helicene }\end{array}$ & $\begin{array}{l}\text { Solution } \\
\text { processed } \\
\text { single layer }\end{array}$ & No & green & $\begin{array}{l}550- \\
625\end{array}$ & 0.2 & 3000 & 3.67 & 1.1 & 1 \\
\hline $\begin{array}{l}\text { PVK/OXD-7 } \\
\text { with Eu } \\
\text { complex }\end{array}$ & $\begin{array}{l}\text { Solution } \\
\text { processed } \\
\text { single layer }\end{array}$ & Yes & orange & $\begin{array}{l}595 \\
612\end{array}$ & $\begin{array}{l}073- \\
0.79 \\
0.09- \\
0.15\end{array}$ & 3 & 0.005 & 0.0067 & 3 \\
\hline $\begin{array}{l}\text { mCP with } \\
\text { Ir complex }\end{array}$ & $\begin{array}{l}\text { Vacuum } \\
\text { sublimed } \\
\text { multilayer } \\
\text { stack }\end{array}$ & Yes & green & $\begin{array}{l}480- \\
540^{a}\end{array}$ & 0.0026 & $n / a$ & $\mathrm{n} / \mathrm{a}$ & $n / a$ & 4 \\
\hline $\begin{array}{l}\text { PVK/OXD-7 } \\
\text { with } 15 \text { wt\% } \\
(-)-1\end{array}$ & $\begin{array}{l}\text { Solution } \\
\text { processed } \\
\text { single layer }\end{array}$ & Yes & red & $\begin{array}{l}575- \\
675\end{array}$ & 0.38 & 222 & 0.25 & 0.11 & $\begin{array}{l}\text { This } \\
\text { work }\end{array}$ \\
\hline $\begin{array}{l}\text { PVK/OXD-7 } \\
\text { with } 15 \text { wt\% } \\
\text { (+)-1 }\end{array}$ & $\begin{array}{l}\text { Solution } \\
\text { processed } \\
\text { single layer }\end{array}$ & Yes & red & $\begin{array}{l}575- \\
675\end{array}$ & 0.22 & 296 & 0.17 & 0.073 & $\begin{array}{l}\text { This } \\
\text { work }\end{array}$ \\
\hline $\begin{array}{l}\text { PVK/OXD-7 } \\
\text { with } 12 \text { wt\% } \\
\text { racemic }( \pm)-1\end{array}$ & $\begin{array}{l}\text { Solution } \\
\text { processed } \\
\text { single layer }\end{array}$ & Yes & red & $\begin{array}{l}575- \\
675\end{array}$ & 0 & 229 & 0.52 & 0.16 & $\begin{array}{l}\text { This } \\
\text { work }\end{array}$ \\
\hline
\end{tabular}

${ }^{a}$ Based on PL data.

\section{Materials and Methods}

Platinahelicene ( \pm )-1 was synthesised according to the synthetic route developed by the groups of Crassous, Autschbach, and Réau. ${ }^{5}$ The only deviation from this route was the synthesis of 2methoxy-5-(pyridin-2-yl)benzaldehyde (S1), which was synthesised according to the procedure below. Electrochemical measurements were performed on an Autolab PGSTAT101 using a platinum wire working electrode and a $\mathrm{Ag} / \mathrm{Ag}^{+}$reference electrode. $\mathrm{HRMS}$ measurements were obtained on a Thermo Scientific Q-Exactive/Dionex Ultimate 3000 system. Flash chromatography was performed on Merck or Fluorochem Silica Gel 40-63 $\mu \mathrm{m}$ particle size using a forced flow of eluent at 0.3-0.5 bar pressure. ${ }^{6}$ PVK (poly(9-vinylcarbazole), CAS 25067-59-8, MW approx. 1,100,000) was purchased from Sigma Aldrich and used without further purification. OXD-7 (1,3-bis[2-(4-tert-butylphenyl)-1,3,4oxadiazol-5-yl]benzene, CAS 138372-67-5) was synthesised according to a literature procedure. ${ }^{7}$ HPLC grade solvents were obtained from Sigma Aldrich and used without further purification. Deionised water was obtained from a Merck Millipore RiOs 3 system and deaerated $\left(\mathrm{N}_{2}\right.$ sparging, 20 
minutes) before use. Acetonitrile was obtained from Sigma Aldrich; it was used without further purification but deaerated ( $\mathrm{N}_{2}$ sparging, 20 minutes) before use. NMR measurements were performed on a Bruker AV400 spectrometer. Chemical shifts were referenced to the residual proton solvent peaks $\left({ }^{1} \mathrm{H}: \mathrm{CDCl}_{3}, \delta 7.26\right)$, solvent ${ }^{13} \mathrm{C}$ signals $\left(\mathrm{CDCl}_{3}, \delta 77.16\right) \cdot{ }^{8}$ Signals are listed in ppm, and multiplicity identified as $\mathrm{s}=$ singlet, $\mathrm{br}=$ broad, $\mathrm{d}=$ doublet, $\mathrm{t}=$ triplet, $\mathrm{q}=$ quartet, quin = quintet, $\mathrm{sep}$ = septet, $\mathrm{m}=$ multiplet; coupling constants in $\mathrm{Hz}$; integration. Concentration under reduced pressure was performed by rotary evaporation at $25-30^{\circ} \mathrm{C}$ at appropriate pressure. Purified compounds were further dried under high vacuum (0.1-0.01 mbar). ITO substrates were obtained from Thin Film Devices, USA ( $12.0 \times 12.0 \mathrm{~mm}, 1.1 \mathrm{~mm}$ thickness, Eagle XG glass, $1450 \AA$ ( $\pm 100 \AA$ ) ITO coating, PN \#550; using a Bruker Dektak Profiler, the ITO layer was determined to be approximately $1350 \AA$ thick). A mounted zero-order quarter-wave plate (WPQ05M-633) and a mounted wire-grid linear polarizer (WP25M-VIS) were purchased from Thorlabs.

\section{Electrochemical measurements}

Electrochemical measurements were performed using a freshly prepared solution of $\mathrm{Bu}_{4} \mathrm{NPF}_{6}$ in anhydrous acetonitrile $(0.10 \mathrm{M})$ with $( \pm)-1(1 \mathrm{mM})$.

Although other approaches have been used to calculate the absolute HOMO energy based on electrochemical data, ${ }^{9}$ the conversion reported by the Forrest group ${ }^{10}$ has a better correlation between electrochemical data and ionization potential and afforded a better fit between optical and electrochemical bandgap in our case. In the Forrest method, the HOMO energy is calculated using the equation $E_{\text {НОмо }}=-1.4 \times q V_{\mathrm{CV}}-4.6 \mathrm{eV}$, with $V_{\mathrm{CV}}$ being the average between the peak for the oxidation of the sample and the peak for the reduction of the oxidized sample, referenced to ferrocene. As the oxidation of $\mathbf{1}$ is irreversible, $\mathrm{V}_{\mathrm{CV}}$ was approximated as $E_{1 / 2}$ ox $=0.5 \mathrm{~V}$ (which in turn was calculated from $\left.E_{\mathrm{p} / 2}\right){ }^{11}$ Plugging this value into the Forrest equation affords $E_{\mathrm{HOMO}}=$ $-(1.4 \times 1 \mathrm{e} \times 0.5 \mathrm{~V})-4.6 \mathrm{eV}=-5.3 \mathrm{eV}$. Following the same procedure for the first reduction curve affords $E_{1 / 2 \text { red }}=-1.5 \mathrm{~V}$ and $E_{\mathrm{LUMO}} \mathrm{e}-\mathrm{chem}=-2.5 \mathrm{eV}$. This value for the LUMO energy is remarkably close to that calculated from $E_{\text {Hомо }}$ and the optical bandgap $\left(E_{\mathrm{LUMO}}\right.$ opt $\left.=-2.6 \mathrm{eV}\right)$. 
Figure S1 Oxidation Wave of Pt complex ( \pm )-1.

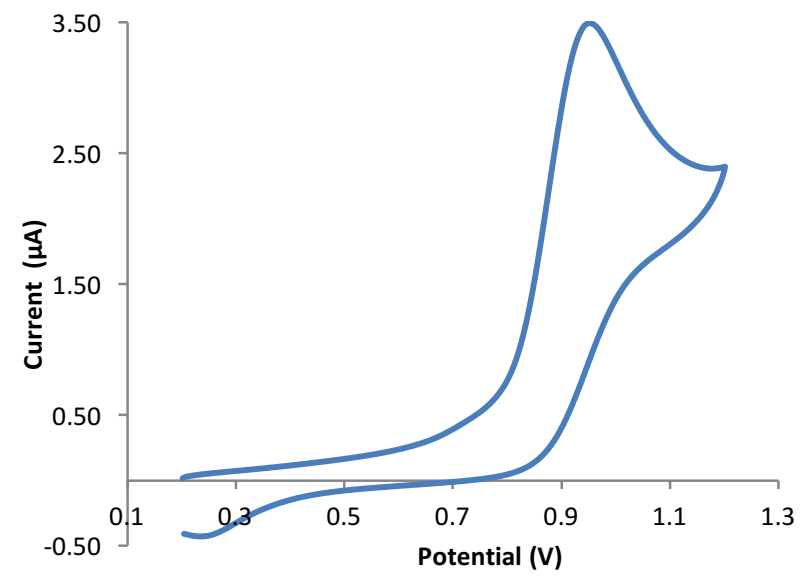

Figure S2 Oxidation of ( \pm )-1 with ferrocene as internal standard.

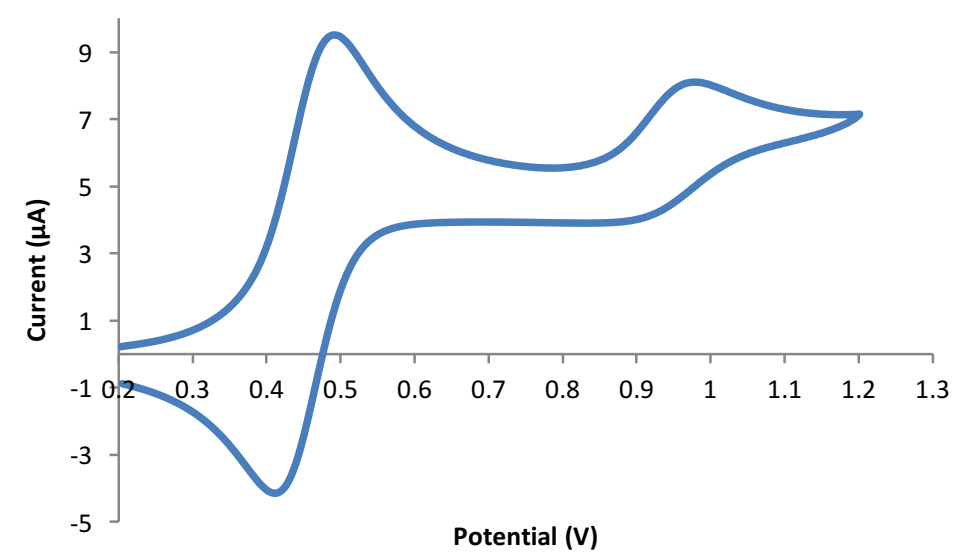

Figure S3 Cyclic Voltammetry of $( \pm)-1$ with ferrocene as internal standard.

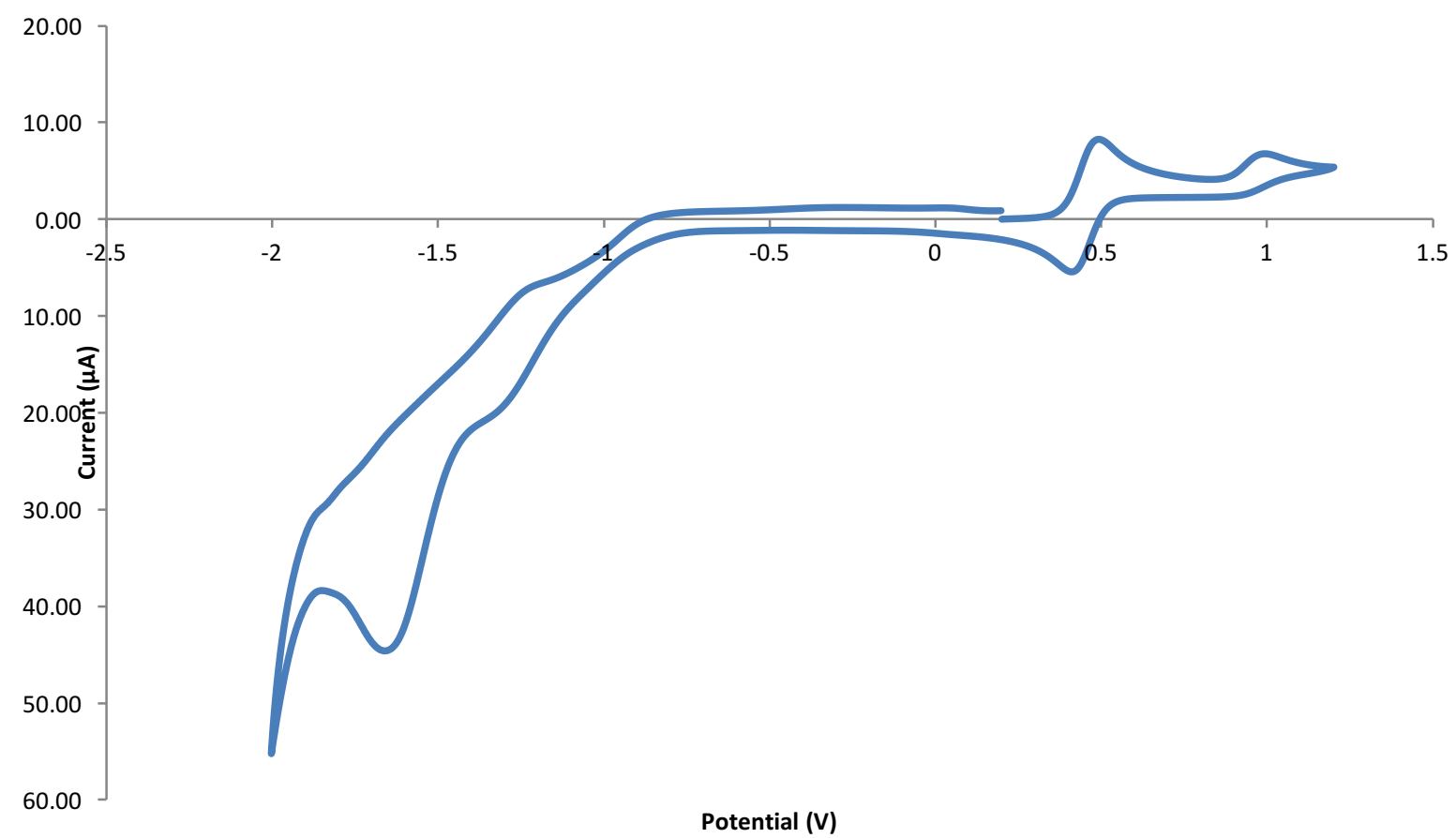




\section{Enantiomer Resolution by Chiral HPLC}

Analytical and preparatory HPLC runs were performed on a Jasco PU-986 system with a MD-1510 detector, an AS-951 autosampler, a semi-prep Daicel Chiralpak IE column $10 \times 250 \mathrm{~mm}, 5 \mu \mathrm{m}$ and eluting with $30: 70$ hexanes:DCM, $5 \mathrm{~mL} / \mathrm{min}$. Samples were dissolved in a 30:70 mixture of hexanes:DCM. For prep scale, 5-10 mg of ( \pm )-1 were injected at a time.

Figure S4 HPLC trace of racemic $( \pm)-1$.

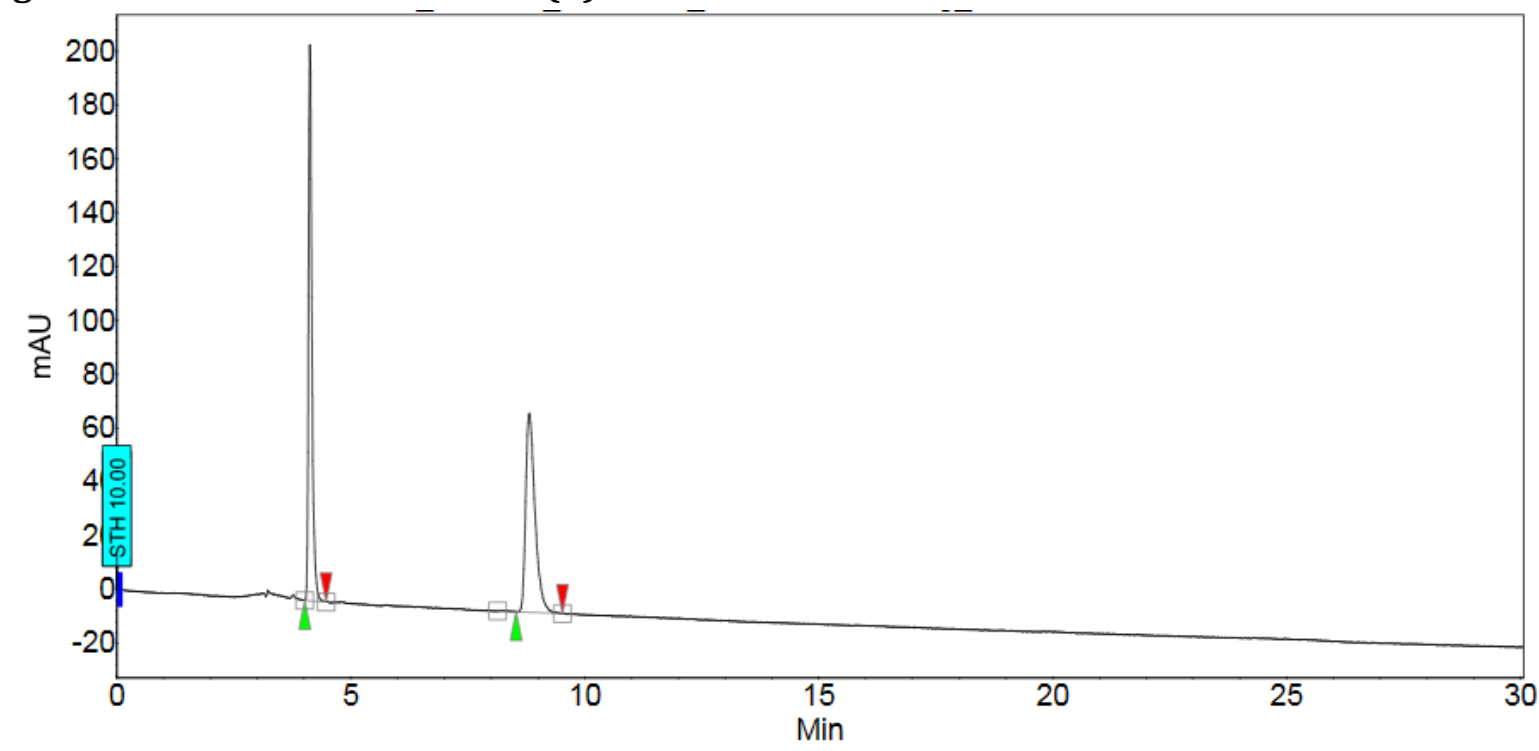

Peak results :

\begin{tabular}{|c|l|r|r|r|r|r|}
\hline Index & Name & $\begin{array}{r}\text { Time } \\
{[\text { Min] }]}\end{array}$ & $\begin{array}{r}\text { Quantity } \\
{[\% \text { Area] }}\end{array}$ & $\begin{array}{r}\text { Height } \\
{[\mathrm{mAU}]}\end{array}$ & $\begin{array}{r}\text { Area } \\
{[\mathrm{mAU} . \mathrm{Min}]}\end{array}$ & $\begin{array}{r}\text { Area \% } \\
{[\%]}\end{array}$ \\
\hline \hline 1 & UNKNOWN & 4.120 & 50.32 & 206.5 & 17.3 & 50.325 \\
\hline 2 & UNKNOWN & 8.813 & 49.68 & 73.9 & 17.0 & 49.675 \\
\hline & & & & & & \\
\hline Total & & & 100.00 & 280.4 & 34.3 & 100.000 \\
\hline
\end{tabular}


Figure S5 HPLC trace of first-eluting (+)-1 after chiral resolution.

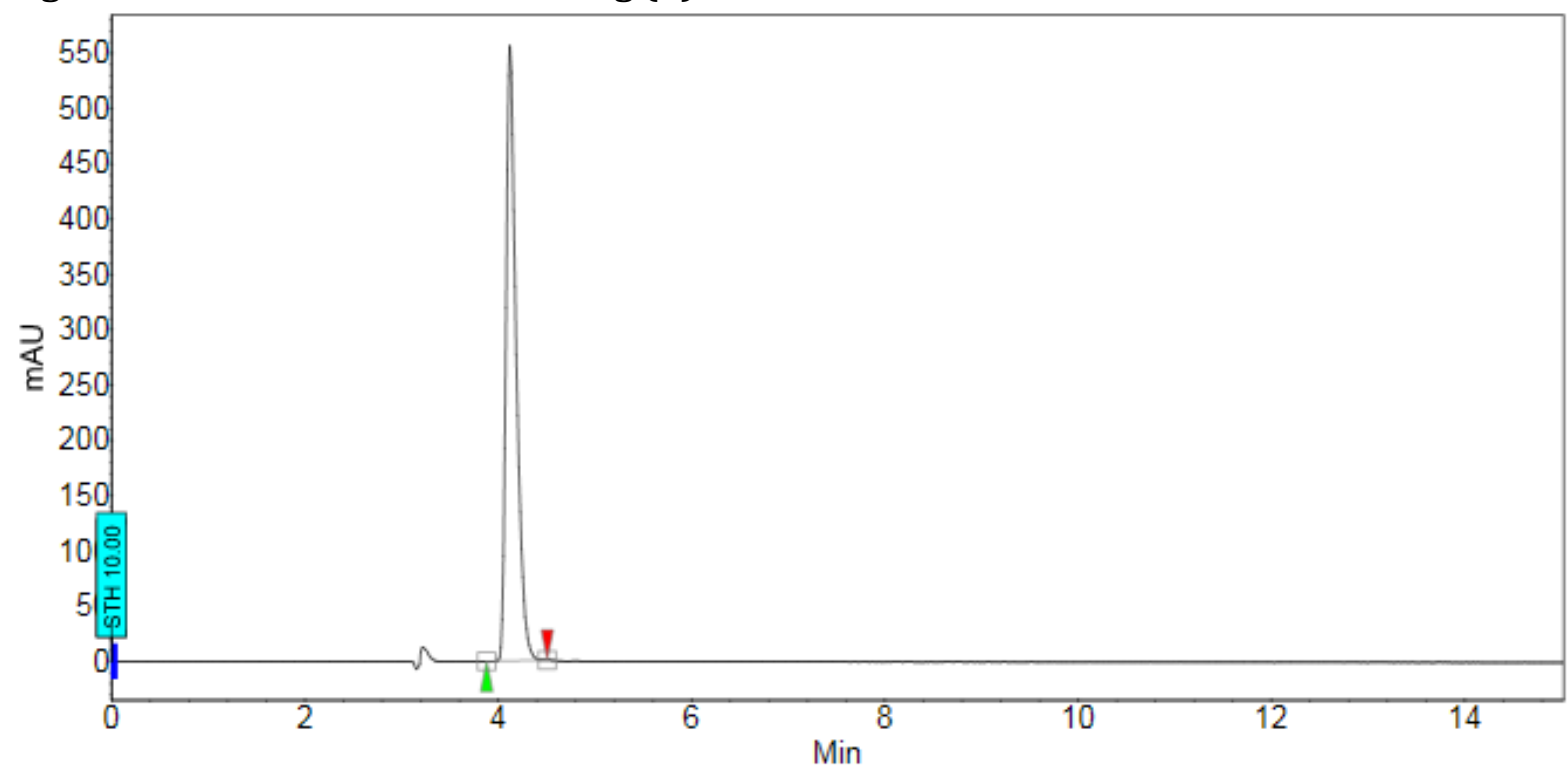

\section{Peak results :}

\begin{tabular}{c|l|r|r|r|r|r|}
\hline Index & Name & $\begin{array}{r}\text { Time } \\
{[\text { Min] }]}\end{array}$ & $\begin{array}{r}\text { Quantity } \\
{[\% \text { Area] }}\end{array}$ & $\begin{array}{r}\text { Height } \\
{[\mathrm{mAU}]}\end{array}$ & $\begin{array}{r}\text { Area } \\
{[\text { [mAU.Min] }}\end{array}$ & $\begin{array}{r}\text { Area \% } \\
{[\%]}\end{array}$ \\
\hline 1 & UNKNOWN & 4.120 & 100.00 & 556.4 & 68.2 & 100.000 \\
\hline & & & & & & \\
\hline Total & & & 100.00 & 556.4 & 68.2 & 100.000 \\
\hline
\end{tabular}

FigureS6 HPLC trace of second-eluting (-)-1 after chiral resolution.

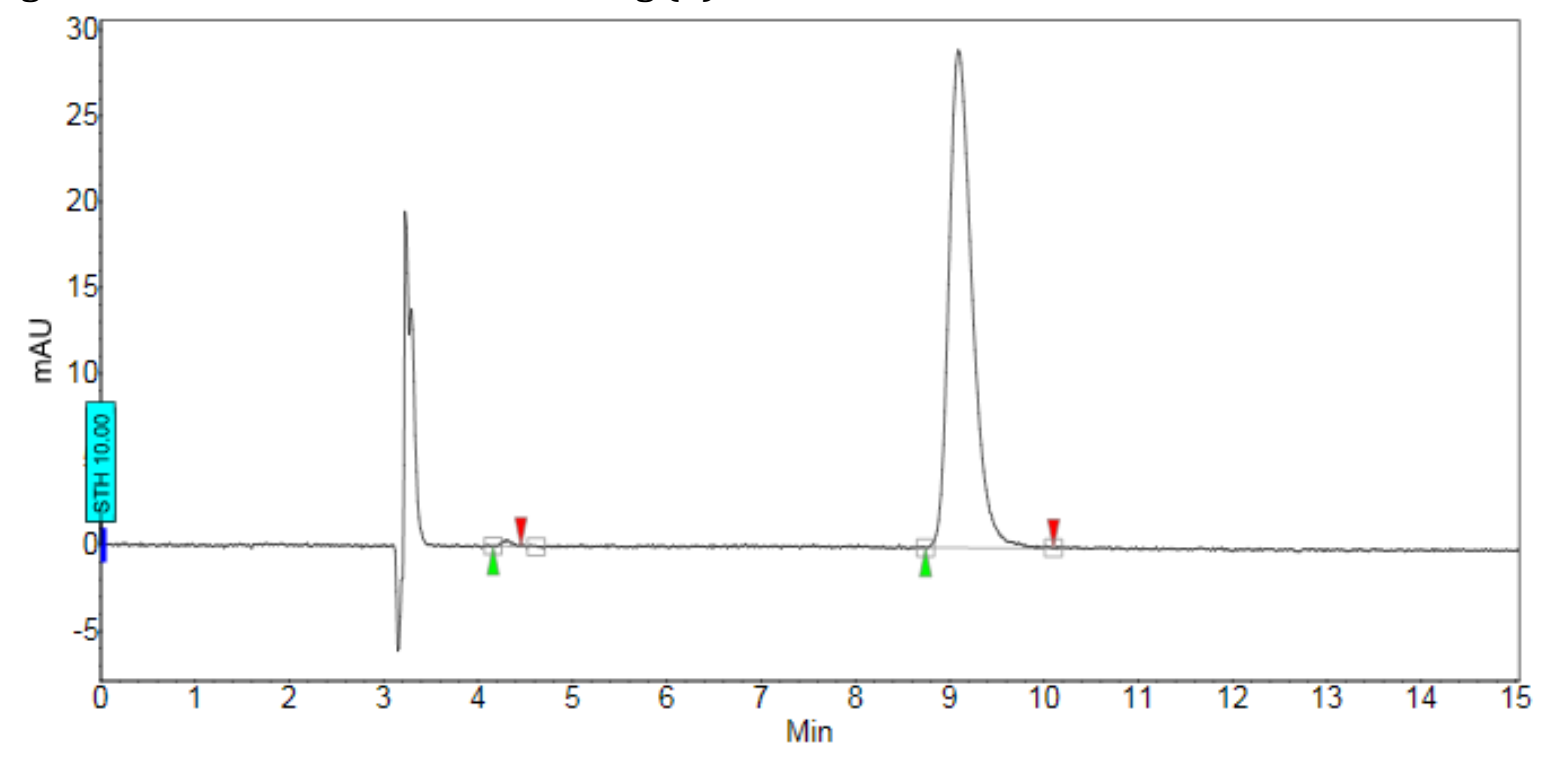

Peak results :

\begin{tabular}{|c|l|r|r|r|r|r|}
\hline Index Name & $\begin{array}{r}\text { Time } \\
{[\text { Min] }}\end{array}$ & $\begin{array}{r}\text { Quantity } \\
{[\% \text { Area }]}\end{array}$ & $\begin{array}{r}\text { Height } \\
{[\text { [mAU] }}\end{array}$ & $\begin{array}{r}\text { Area } \\
\text { [mAU.Min] }\end{array}$ & $\begin{array}{r}\text { Area \% } \\
{[\%]}\end{array}$ \\
\hline 1 & UNKNOWN & 4.307 & 0.55 & 0.3 & 0.0 & 0.551 \\
\hline 2 & UNKNOWN & 9.093 & 99.45 & 29.0 & 8.3 & 99.449 \\
\hline & & & & & & \\
\hline Total & & & 100.00 & 29.3 & 8.3 & 100.000 \\
\hline
\end{tabular}




\section{Sign convention of left- and right-handed circularly polarized light}

Different conventions are used to define the handedness of circularly polarized light. These depend on whether the system is observed from the point of view of the light source looking towards the receiver, or from the receiver looking back towards the light source. Different equations are also used to define the handedness. Whilst convention dictates that the electromagnetic wave travels in a positive direction up the $z$-axis, there are two different ways the $y$-axis can be arranged relative to the $x$-axis. This leads to two different equations for each handedness.

To deal with this we will define the conventions used in this work. We will also clearly describe the experimental setup used to measure the different handedness of circularly polarized light.

\section{Convention used in this work}

We will take the perspective of the source looking at the receiver.

We will assume the circularly polarized electromagnetic wave travels in a positive direction along the $z$-axis from $z=0$ at the source. Looking down the $z$-axis towards the receiver we will assume the $x$ axis is vertical (this is at $0^{\circ} / 12 \mathrm{o}^{\prime}$ clock). We will assume the $y$-axis is horizontal and to the right (this is at $90^{\circ} / 3$ o'clock).

Right-handed light. Looking from the source towards the receiver, at any fixed point on the z-axis the electric field vector will rotate in time in a clockwise direction. In terms of the two linearly polarized electric field components $E_{x}$ and $E_{y}$ which make up the circularly polarized electromagnetic wave, at any fixed point in time travelling up the z-axis away from the source the component in the $x$-direction $E_{x}$ will lead the component in the $y$-direction $E_{y}$ by a quarter wavelength.

Left-handed light. Looking from the source towards the receiver, at any fixed point on the z-axis the electric field vector will rotate in time in an anticlockwise direction. In terms of the two linearly polarized electric field components $E_{x}$ and $E_{y}$ which make up the circularly polarized electromagnetic wave, at any fixed point in time travelling up the z-axis away from the source the component in the $x$-direction $E_{x}$ will lag behind the component in the $y$-direction $E_{y}$ by a quarter wavelength.

\section{Experimental convention used in this work to measure circularly polarized photoluminescence and electroluminescence.}

The fast axis of the quarter wave plate lines up on the $x$-axis (at $0^{\circ} / 12$ o'clock). The slow axis of the quarter wave plate lines up on the $y$-axis (at $90^{\circ} / 3$ o'clock).

To detect right-handed CP light: The linear polarizer is placed at $135^{\circ} / 4.30$ AM-PM. The electroluminescent or photoluminescent intensity measured with this configuration is assumed to be equal to $I_{R}$.

To detect left-handed CP light: The linear polarizer is placed at $45^{\circ} / 1.30$ AM-PM. Electroluminescent or photoluminescent intensity measured with this configuration is assumed to be equal to $I_{L}$. 

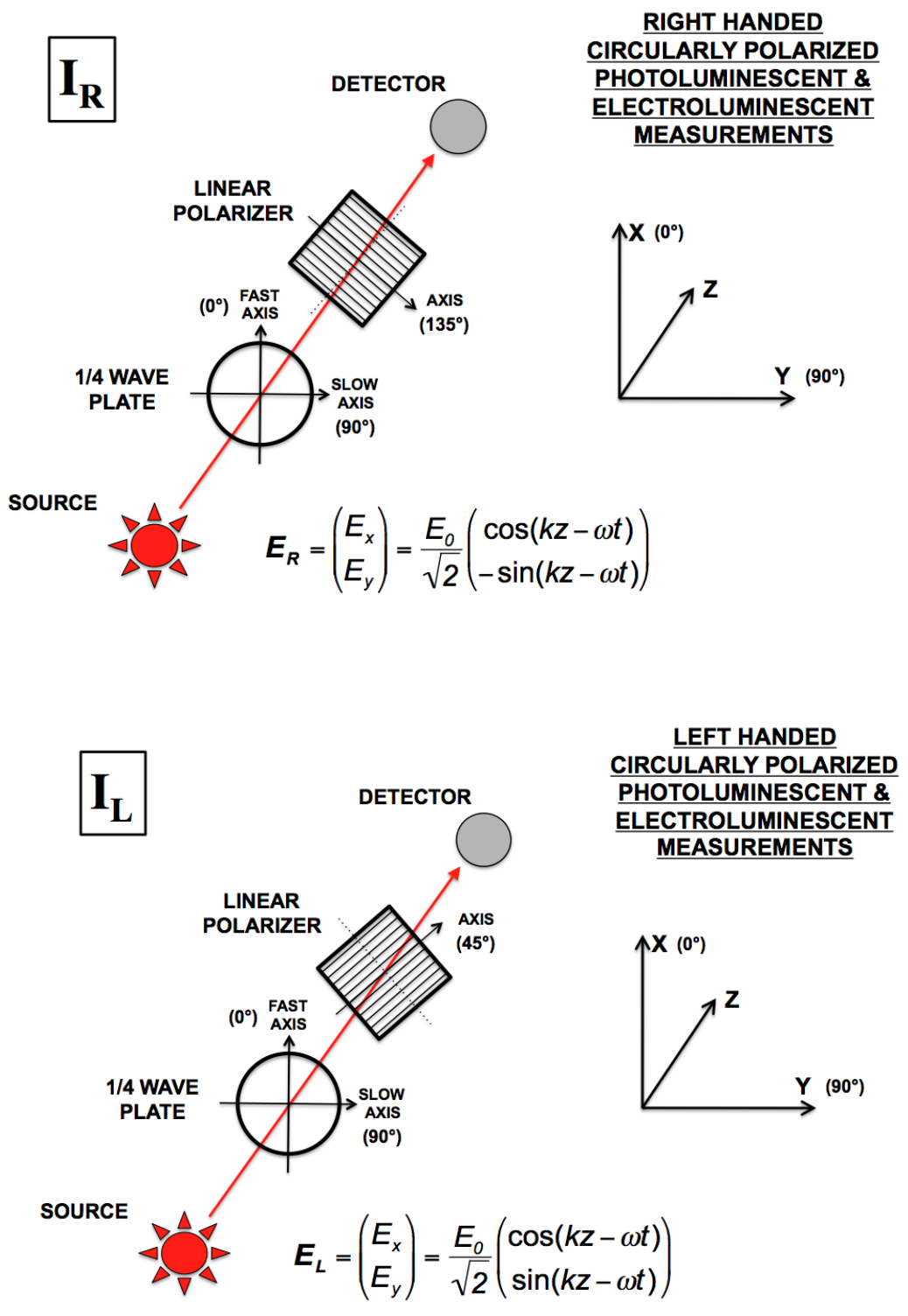

\section{Experimental convention used in circular dichroism measurements}

The raw data collected in the Circular Dichroism measurements using a Chirascan (Applied Photophysics) instrument follows a convention that is opposite to ours. To stay consistent in our data presentation, the sign of the raw data was inverted so that all graphs presented by us match our definition stated above.

\section{Discussion of Dissymmetry Factor and Anti-Glare Filter}

The dissymmetry factor is defined as

$$
g=2 \frac{I_{L}-I_{R}}{I_{L}+I_{R}}
$$

For a g-factor of -0.38 , the ratio of $I_{L}$ to $I_{R}$ is 40.5 to 59.5 :

$$
g=2 \frac{40.5-59.5}{40.5+59.5}=2 \frac{-19}{100}=-0.38
$$


In this case, $I_{R}$ is $47 \%$ larger than $I_{L}$.

\section{Explanation of Anti-Glare Filter}

Circular polarizers are the most common method to reduce reflection of external light on the metallic cathode in OLED displays. ${ }^{12}$ Their mechanism is displayed in Figure S7: when unpolarized light passes through the first linear polarizer, approximately $50 \%$ is filtered out. The remaining light of linear polarization passes through a quarterwave plate and is turned into circularly polarized light of one orientation (here: right). Upon reflection at the cathode, the polarization changes to the opposite sign (left). As this left-handed light passes through the quarterwave plate again, it is turned into linearly polarized light that is orthogonal to the orientation of the incoming light. Thus, it cannot pass through the linear polarizer.

Figure S7 Circular polarizer reduces glare by filtering out ambient light.

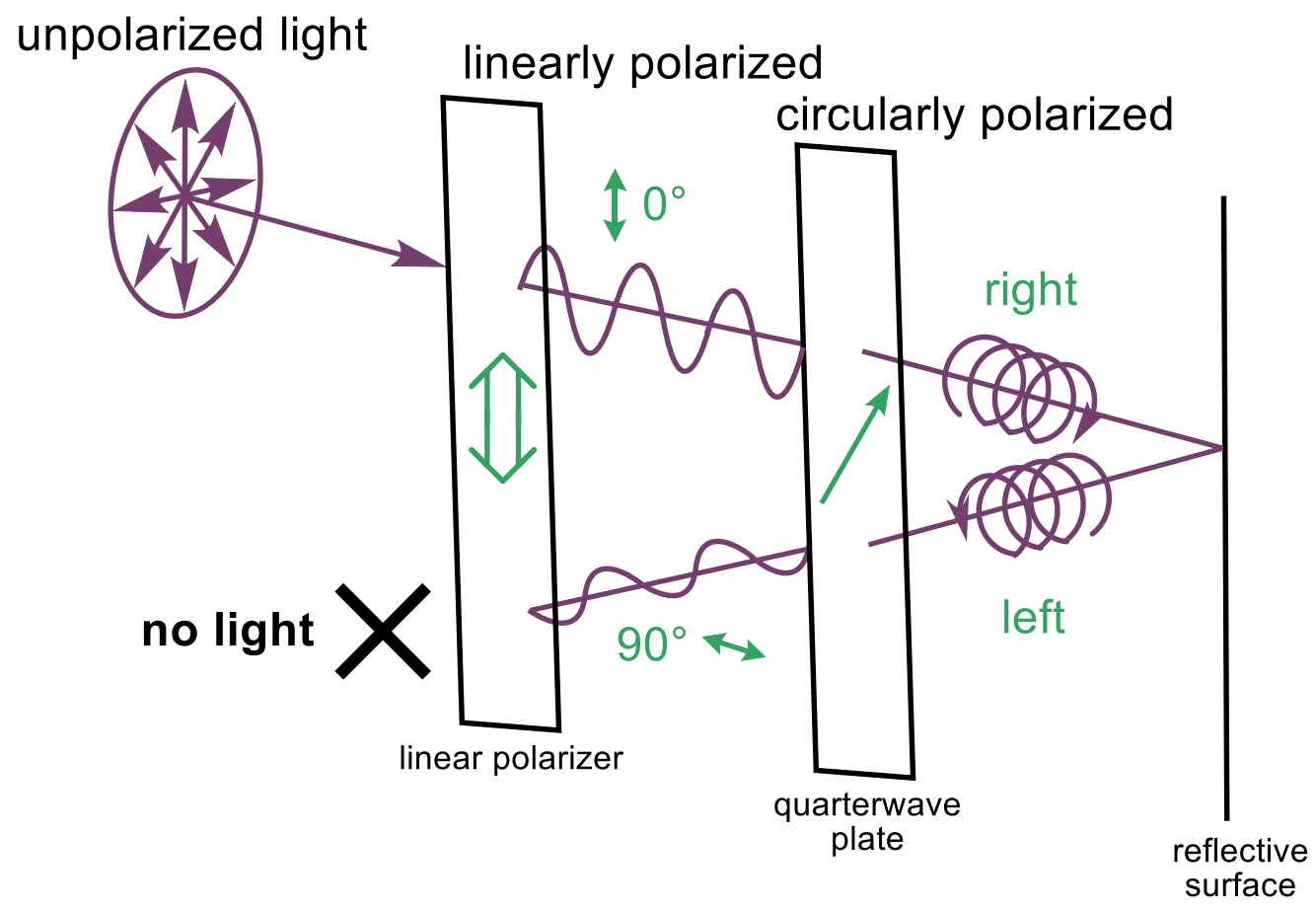

Current OLED displays produce light with no circular polarization. This light will be phase shifted as it passes through the quarterwave plate, but remains unpolarized (see Figure 58 ). Therefore, $50 \%$ of the light will be filtered while passing through the linear polarizer, reducing the perceived brightness of the display. 
Figure S8 Effect of circular polarizer on conventional OLED display brightness. linearly polarized

unpolarized

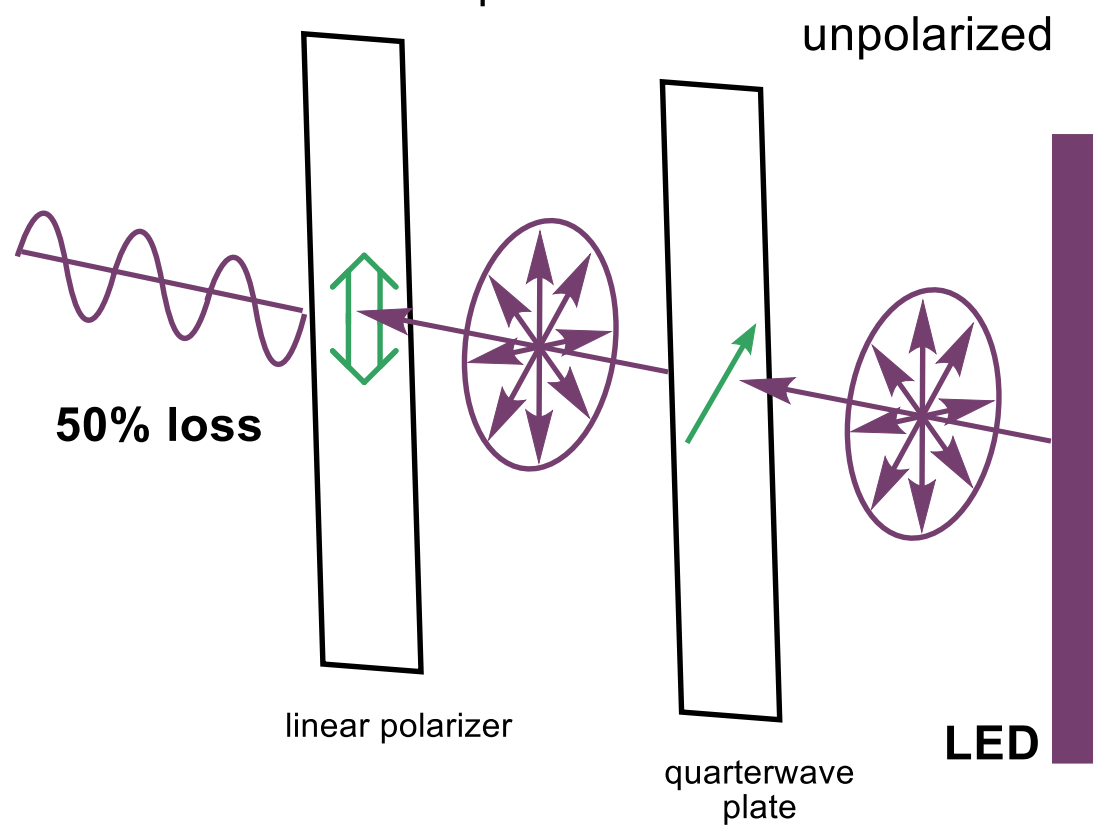

In contrast, no light is lost when CP-OLEDs only emit circularly polarized light of the correct sign (see Figure S9). The quarterwave plate will turn the CP-light into linearly polarized light that is correctly aligned with the linear polarizer and can pass through it without loss in brightness.

Figure S9 CP-OLEDs achieve higher brightness compared to non-polarized emission. linearly polarized

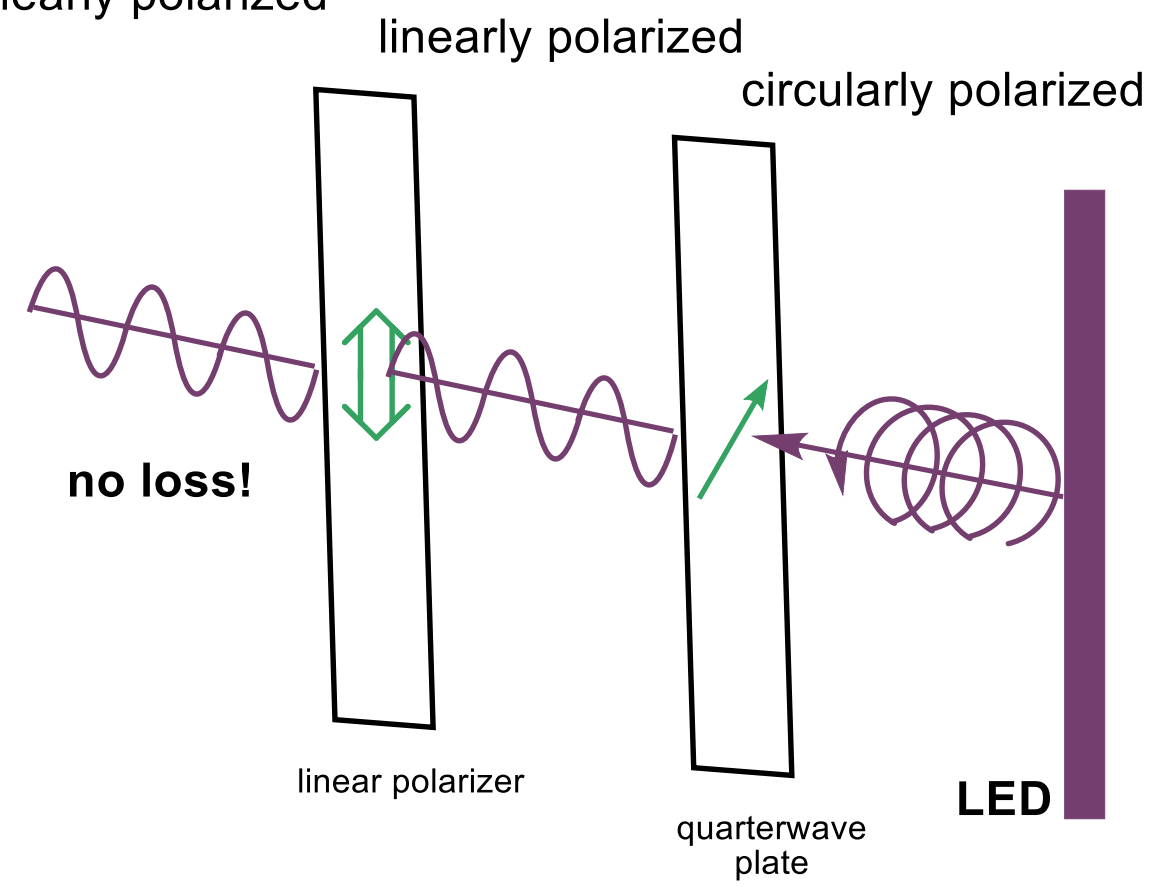

A display featuring OLEDs with full circular polarization (e.g. $\mathrm{I}_{\mathrm{L}}+\mathrm{I}_{\mathrm{R}}=\mathrm{I}_{\mathrm{L}}+0=\mathrm{I}_{\text {total }}, \mathrm{g}_{\mathrm{EL}}=2$ ) will be able to bypass the filter completely with an effective emission equal to the total emission of the device: $\mathrm{I}_{\text {eff }}=\mathrm{I}_{\text {total }}$ (assuming no decrease in outcoupling efficiency). In contrast, for OLEDs with no 
circular polarization, only half the total emission will bypass the filter: $\mathrm{I}_{\mathrm{eff}}=\mathrm{I}_{\mathrm{L}}=\frac{\mathrm{I}_{\text {total }}}{2}$. The maximum $\left|\mathrm{g}_{\mathrm{EL}}\right|$ factor of 0.38 achieved in the current report corresponds to $59.5 \%$ polarization of one sign, $19 \%$ larger than the $50 \%$ polarization expected in conventional OLEDs.

\section{Device Fabrication}

\section{CP-PHOLED Device Fabrication}

In this work, the pre-patterned ITO substrates (Thin Solid Films) were used as a transparent electrode (anode) for the OLED devices. The ITO substrates were cleaned using Acetone and IPA in sequence in ultrasonic bath for $30 \mathrm{~min}$, respectively, and dried in the oven at $110^{\circ} \mathrm{C}$ for $30 \mathrm{~min}$ before use. An AI4083 PEDOT:PSS solution was spun on the ITO coated substrates as a hole injection layer with the thickness of $\approx 60 \mathrm{~nm}$. A mixture of OXD-7:PVK in varying weight ratios $(1: 9,3: 7,5: 5$, $7: 3,9: 1)$ was prepared so that the total weight afforded a $10 \mathrm{mg} / \mathrm{ml}$ chlorobenzene solution. $15 \mathrm{wt} \%$ of enantiopure (+)-1 or (-)-1 relative to OXD-7:PVK was added to the mixture and the resulting solutions were stirred at room temperature overnight. The solutions were then filtered ( $1 \mu \mathrm{m}$ PTFE syringe filter) and spin coated onto the top of the PEDOT:PSS layer to form an active layer of about 60-80 $\mathrm{nm}$ thickness. The spin-speed was $2000 \mathrm{rpm}$ with a duration of $60 \mathrm{~s}$. Then the coated films were transferred to a nitrogen filled glovebox system equipped with a thermal evaporator. The cathode of the OLED devices was defined by the patterned thin metal mask. The device area was formed by the overlap region of the cathode and anode. The cathode of calcium and aluminium were evaporated under a vacuum of $2 \times 10^{-7}$ torr with a thickness of $20 \mathrm{~nm}$ and $100 \mathrm{~nm}$, respectively.

\section{Photophysical and morphology characterization.}

OLED JVL characteristics: A home-written Labview program (by Xuhua Wang) was used to control the Keithley 2400 source-measure-unit and Konica Minolta LS-110 Luminance Meter to record the voltage-current and luminance. The pixel area is $0.045 \mathrm{~cm}^{2}$ by overlapping the anode of ITO with the cathode of $\mathrm{Ca} / \mathrm{Al}$ to form one pixel. Each device has 6 pixels. Both EL and PL spectra were taken by an Ocean Optics USB2000 CCD spectrophotometer. The spectra were corrected against all optics response by the supplier.

An EL spectrum was measured through the ITO side in the forward direction. CP-EL spectra were taken at $10 \mathrm{~mA}$ driving current with a voltage of approximately $12-13 \mathrm{~V}$, depending on the devices. The EL spectra were recorded with no filter as well as with a quarterwave plate and a linear polarizer at 45 or $135^{\circ}$ angles as described above.

The microscope images of thin films were taken using BX51-P-Olympus Polarizing Microscope and the roughness of the films was measured using an AFM Bruker Nanoscope III.

\section{Thin Film Circular Dichroism spectra characterization}

Thin films of 15 wt\% (-)-1 or 15 wt\% (+)-1 in an OXD-7 and PVK mixture (1:1) were prepared on quartz substrates as described above. The CD spectra of the films were measured on a Chirascan instrument by Applied Photophysics using a rectangular cell holder. An empty quartz substrate was used to record the background, which was automatically deducted from the measurements. CD spectra were recorded between 200 and $500 \mathrm{~nm}$ at $1 \mathrm{~nm}$ steps and $1.5 \mathrm{~s}$ measurement time per step. After the first measurement, each sample was rotated by $90^{\circ}$ and measured again to estimate the contribution of scattering or linear polarization to the CD spectra; Figure S14 shows the high 
reproducibility between different films and film orientations. The graphs in Figure 2B and Figure S15 represent the average of one film measured at 0 and $90^{\circ}$. As described in the section on the CP sign convention, the sign of the raw data was inverted so that all graphs presented in this publication follow the same convention.

\section{CP-PL characterization.}

A blue LED $\left(\lambda_{\max }=460 \mathrm{~nm}\right)$ was used to excite the thin film samples used in the CD studies. The detection of the fluorescence was vertical to the incident light to maximise the PL signal. (Different directions of PL collections were also tested.) It was found that $90^{\circ}$ to incident excitation light afforded the best PL signal to noise ratio. The PL spectra were recorded with no filter as well as with a quarterwave plate and a linear polarizer at 45 or $135^{\circ}$ angles as described above. The waveplate was kept close to the sample; the polariser was kept close to the CCD spectrophotometer.

\section{Commission internationale de l'éclairage (CIE) coordinates}

CIE 1931 coordinates were fitted using Matlab and the "CIE Coordinate Calculator" by Prashant Patil (Matlab file exchange file ID \#29620). For the device using 15 wt\% (-)-1 in OXD-7:PVK 1:1, the obtained coordinates are $(0.58,0.41)$.

\section{Device Structure}<smiles>CC(C)(C)c1ccc(-c2nnc(-c3cccc(-c4nnc(-c5ccc(C(C)(C)C)cc5)o4)c3)o2)cc1</smiles>

OXD-7<smiles>CC(C)(C)C(n1c2ccccc2c2ccccc21)C(C)(C)C</smiles>

PVK<smiles></smiles>

$(P)-(+)-1$

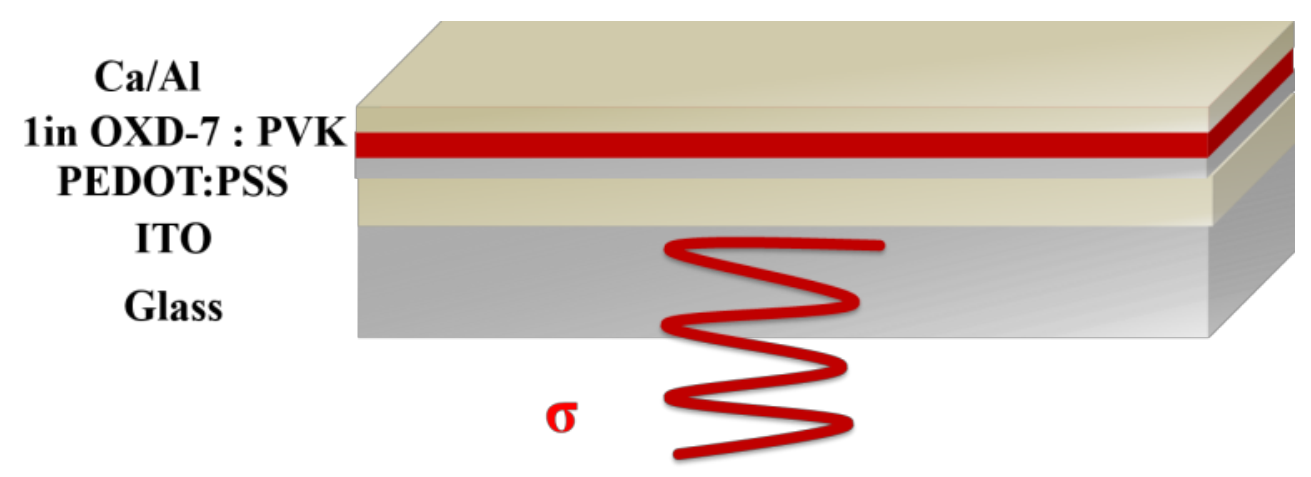


Figure S10 Photograph of a PHOLED (15 wt\% (+)-1 in PVK:OXD-7 1:1 matrix) in operation, no polarisation filters used.

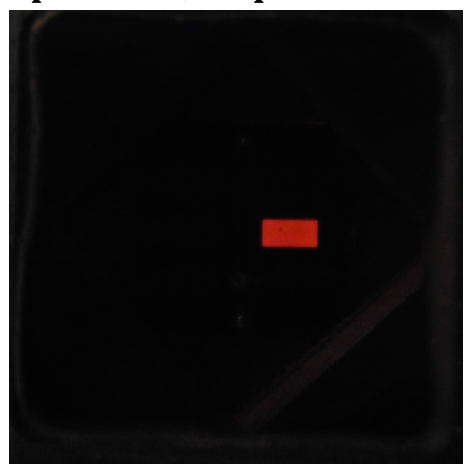

Dimensions of pixel are $1.5 \mathrm{~mm} \times 3 \mathrm{~mm}$

\section{Device Data for Racemic $( \pm)-1$}

Figure S11 J-V-L graph of OLED devices with 12 wt\% racemic ( \pm )-1 in PVK:OXD-7 matrices.

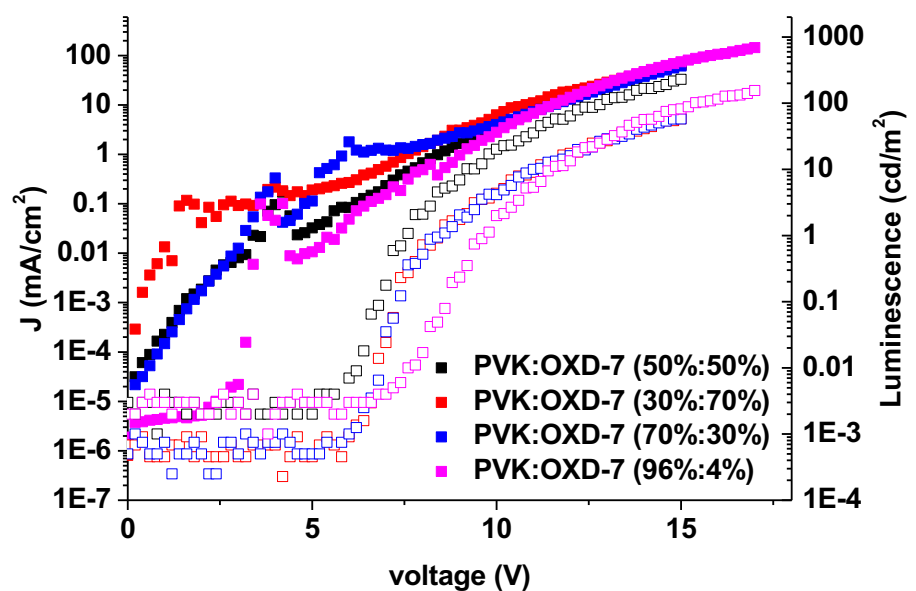

Figure S12 Efficiency of OLED devices with 12 wt\% racemic ( \pm )-1 in PVK:0XD-7 matrices.

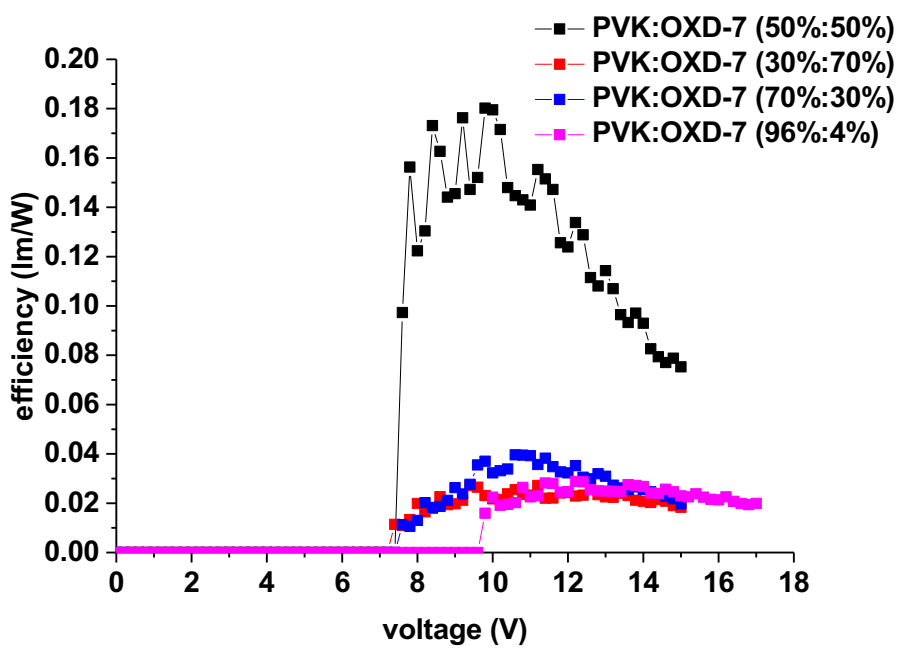


Figure S13 Normalized EL spectra of OLED devices with $12 \mathrm{wt} \%$ racemic $( \pm)-1$ in PVK:OXD-7 matrices.

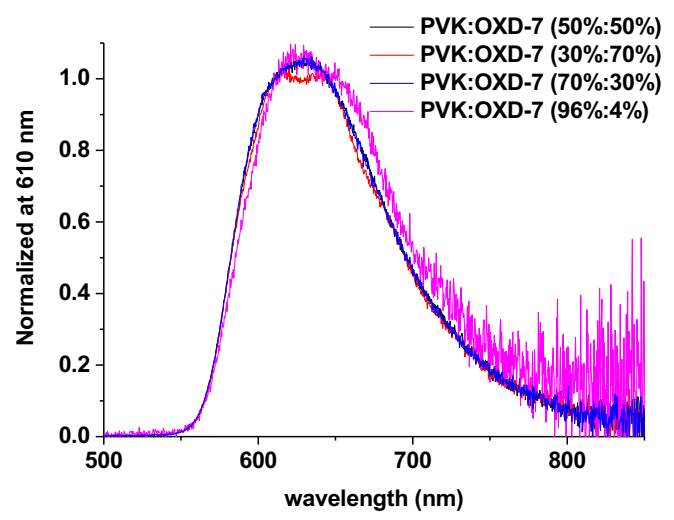

\section{Thin Film Characterization of Enantiopure 1 in OXD-7:PVK Matrix}

Figure S14 Overlay of CD spectra of two thin films (15 wt\% (+)-1, OXD-7:PVK 1:1) at two orientations each $\left(0\right.$ and $\left.90^{\circ}\right)$ shows high reproducibility and negligible scattering or linear polarization.

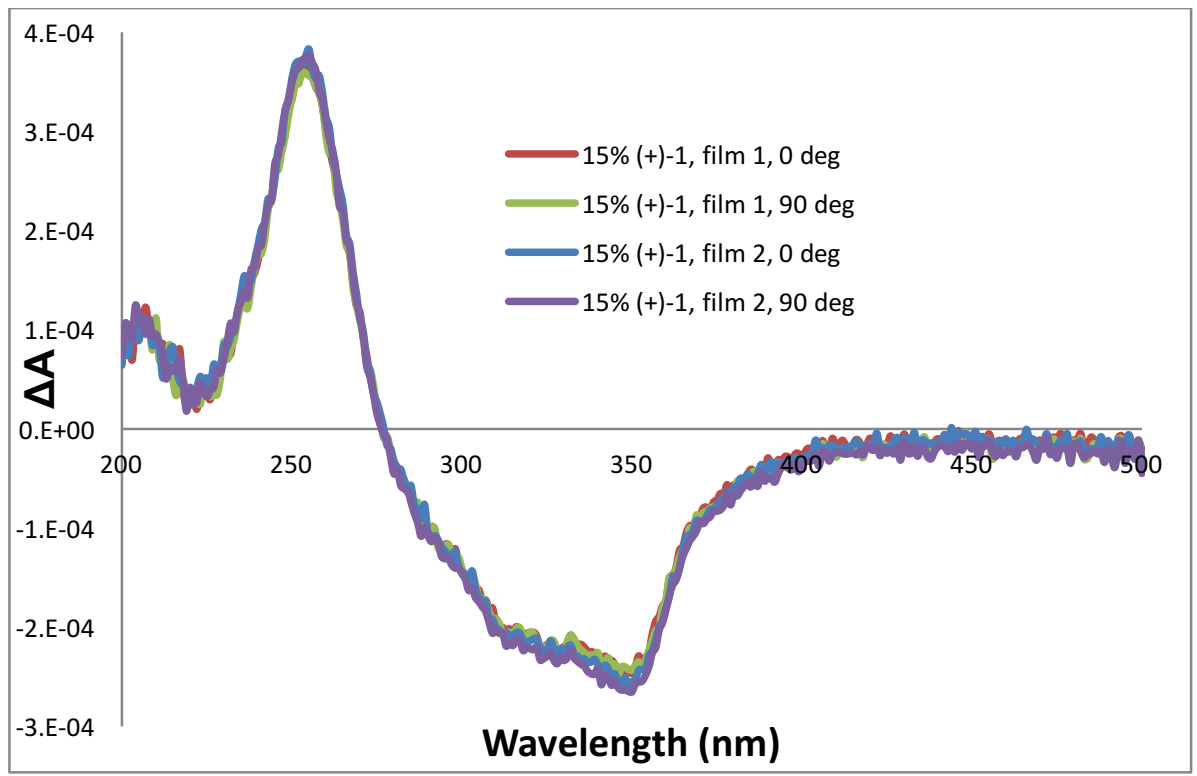


Figure S15 g-factor of $(+)-1$ and (-)-1 in OXD-7:PVK matrix 1:1.

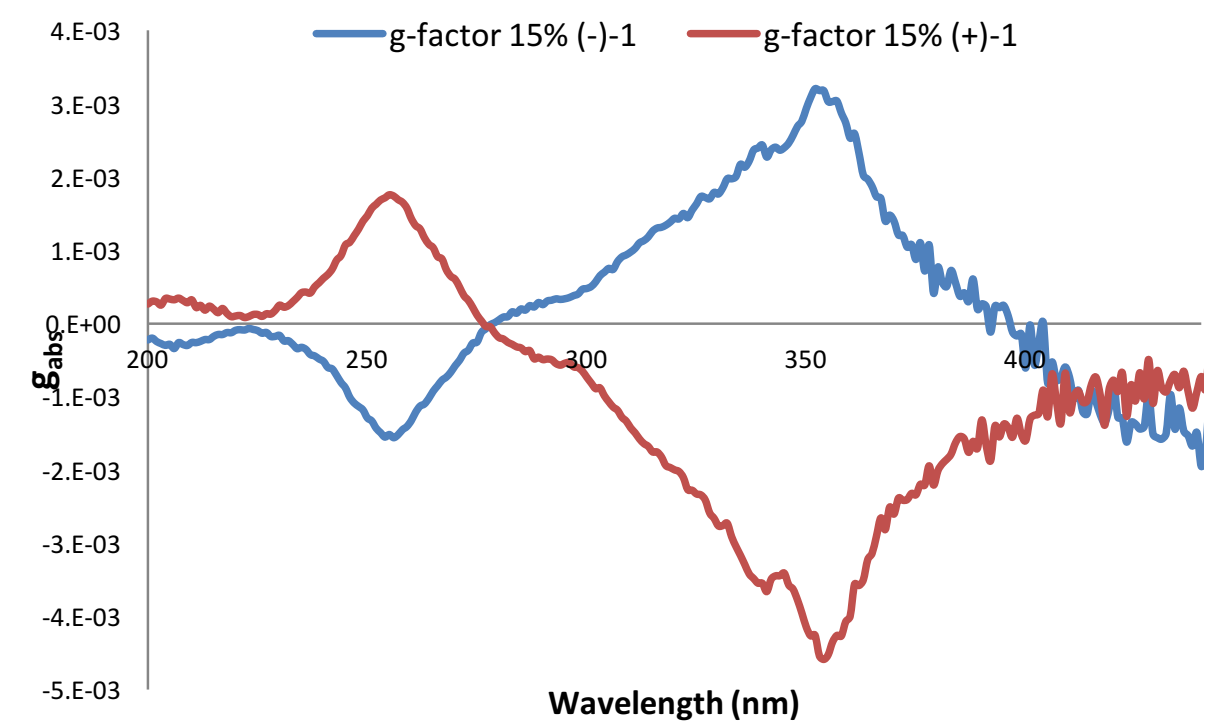

Figure S16 Optical and AF microscopy images of 15 wt\% (-)-1 in OXD-7:PVK 50:50 film, $\mathbf{R}_{\mathbf{q}}=0.424 \mathrm{~nm}$.

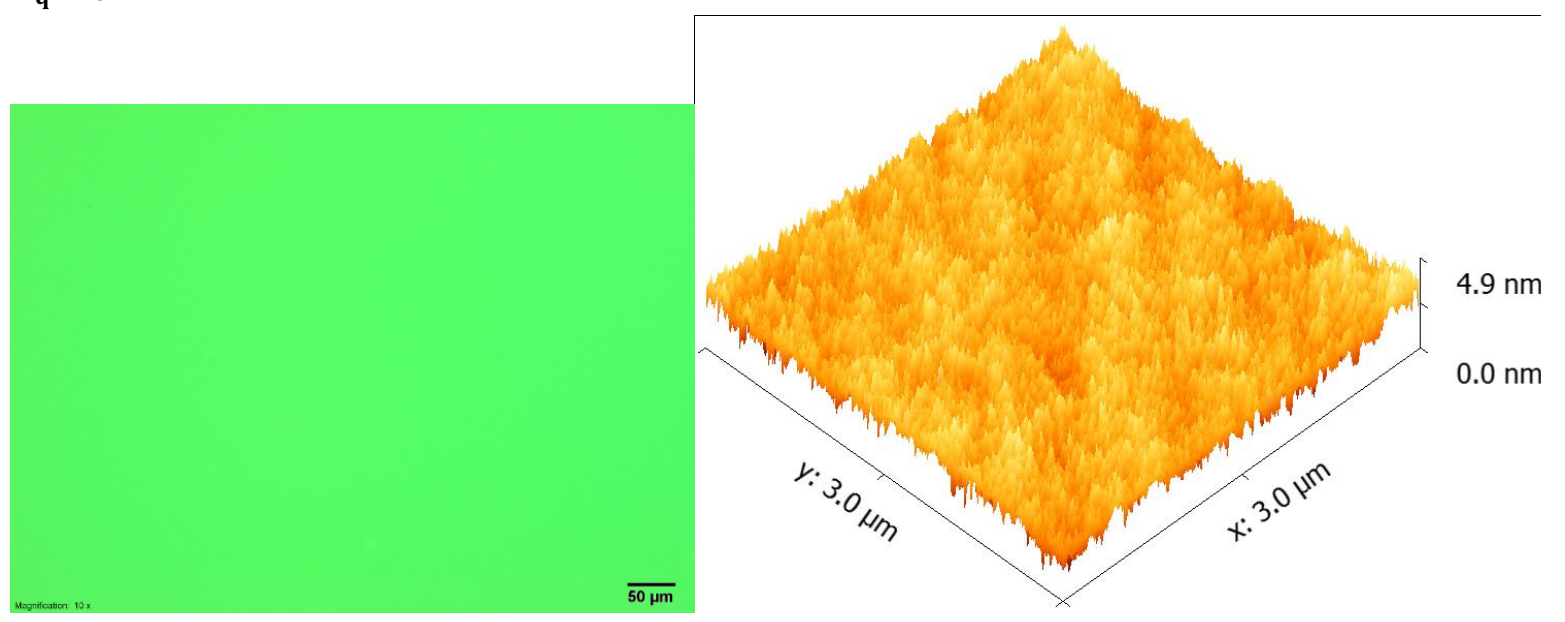

Figure S17 Optical and AF microscopy images of $15 \mathrm{wt} \%(+)-1$ in OXD-7:PVK 50:50 film, $\mathbf{R}_{\mathbf{q}}=0.337 \mathrm{~nm}$.

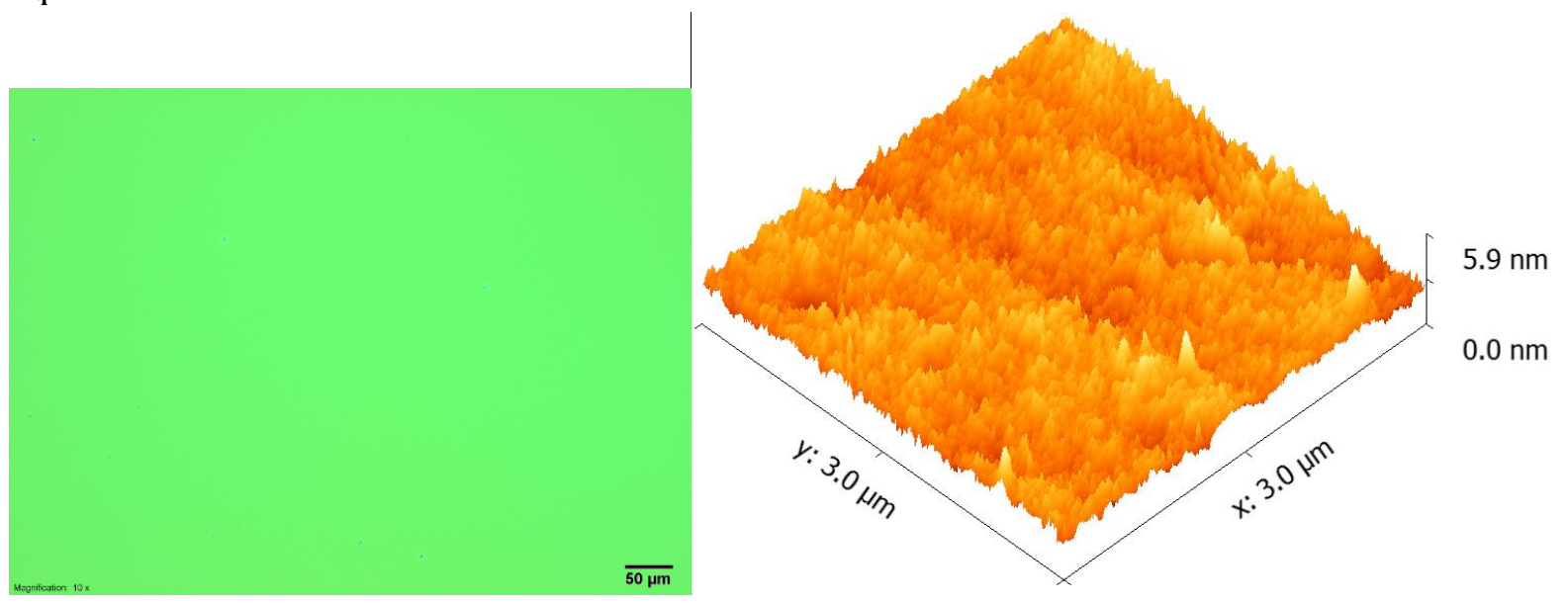




\section{Device Data for Enantiopure 1, Influence of Layer Composition}

\section{g-Factor analysis}

g-Factors as shown in Figure $3 C$ were calculated in Origin Pro 2016 based on the $I_{L}$ and $I_{R}$ components of the circularly polarized light using the equation $g=2 \frac{\mathrm{I}_{L}-\mathrm{I}_{R}}{\mathrm{I}_{\mathrm{L}}+\mathrm{I}_{\mathrm{R}}}$. The reported g-factors represent the mean of all values between 610 and $620 \mathrm{~nm}$ (EL) or 620 and $630 \mathrm{~nm}$ (PL). The difference in $\left|\mathrm{g}_{\mathrm{EL}}\right|$ or $\left|\mathrm{g}_{\mathrm{PL}}\right|$ magnitude between (+)-1 and (-)-1 is likely due to device-to-device variability.

Figure S18 Unfiltered EL spectra of devices with 15 wt\% (-)-1 in varying OXD-7:PVK ratios.

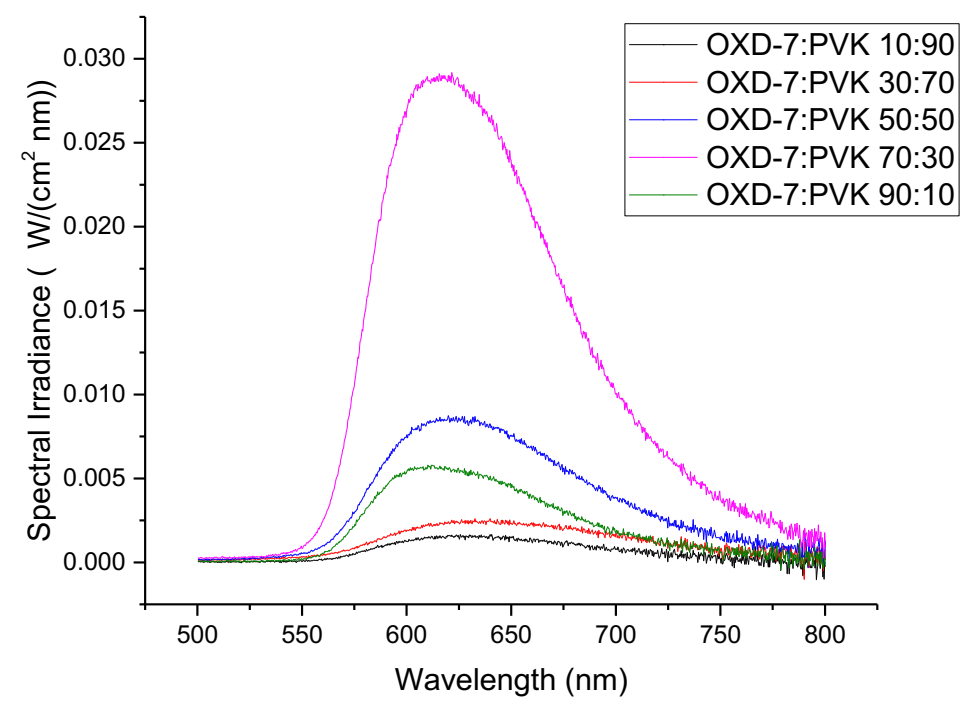

Figure S19 J-V-L graph of OLED device with 15 wt\% (-)-1 in OXD-7:PVK 50:50 matrix.

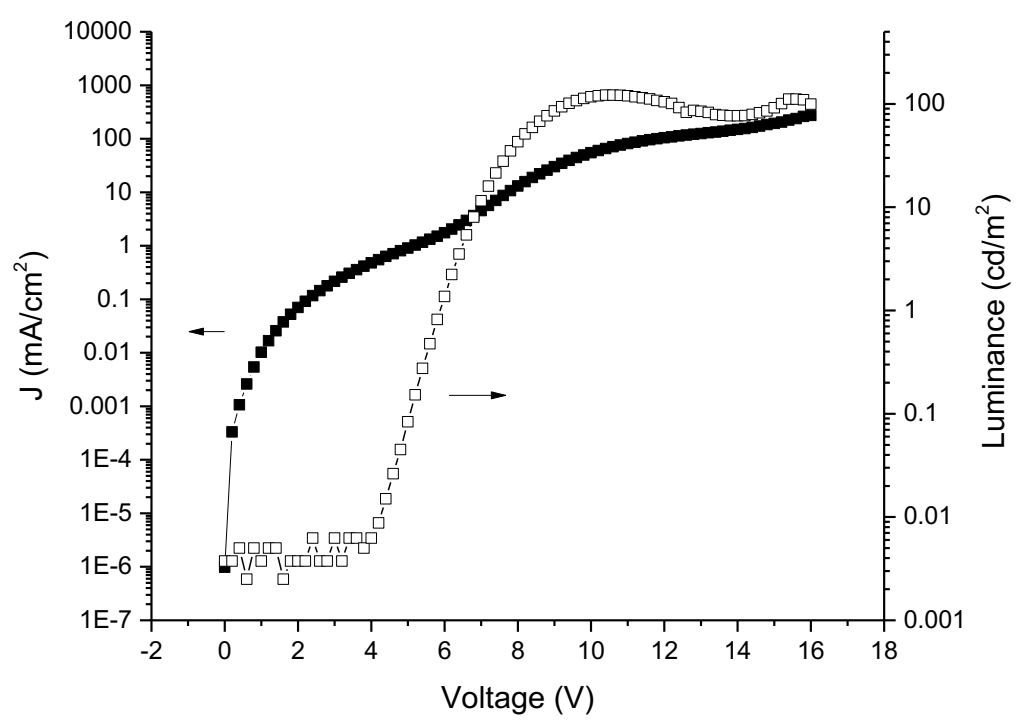


Figure S20 Efficiency of OLED device with $15 \mathrm{wt} \%(-)-1$ in OXD-7:PVK 50:50 matrix.

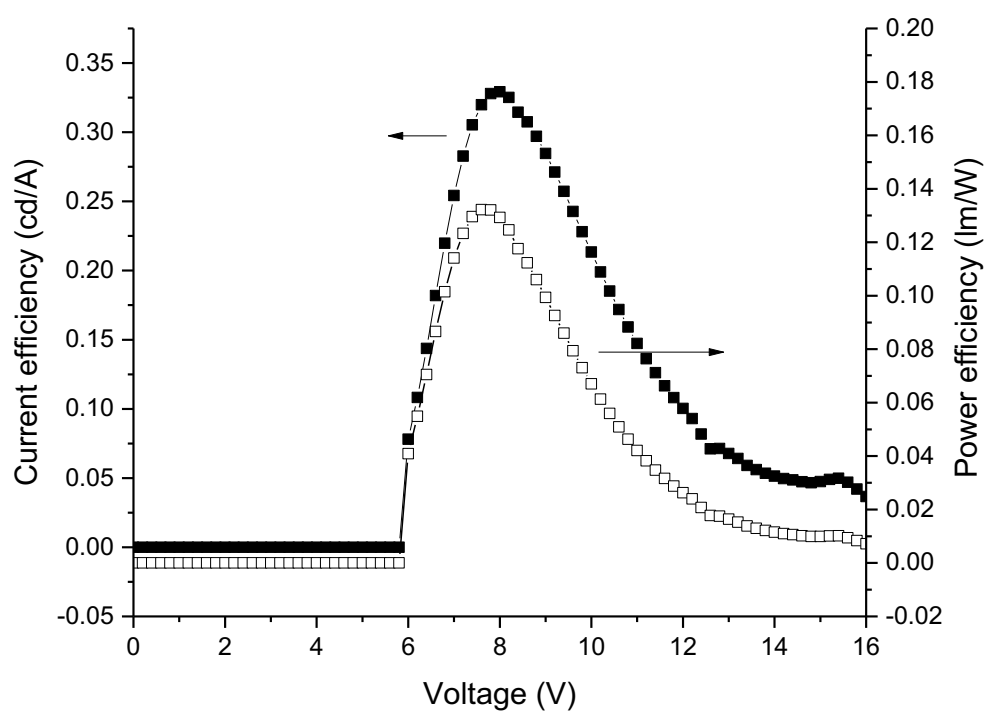

Figure S21 J-V-L graph of OLED device with $15 \mathrm{wt} \%$ (-)-1 in OXD-7:PVK 70:30 matrix from matrix ratio screen.

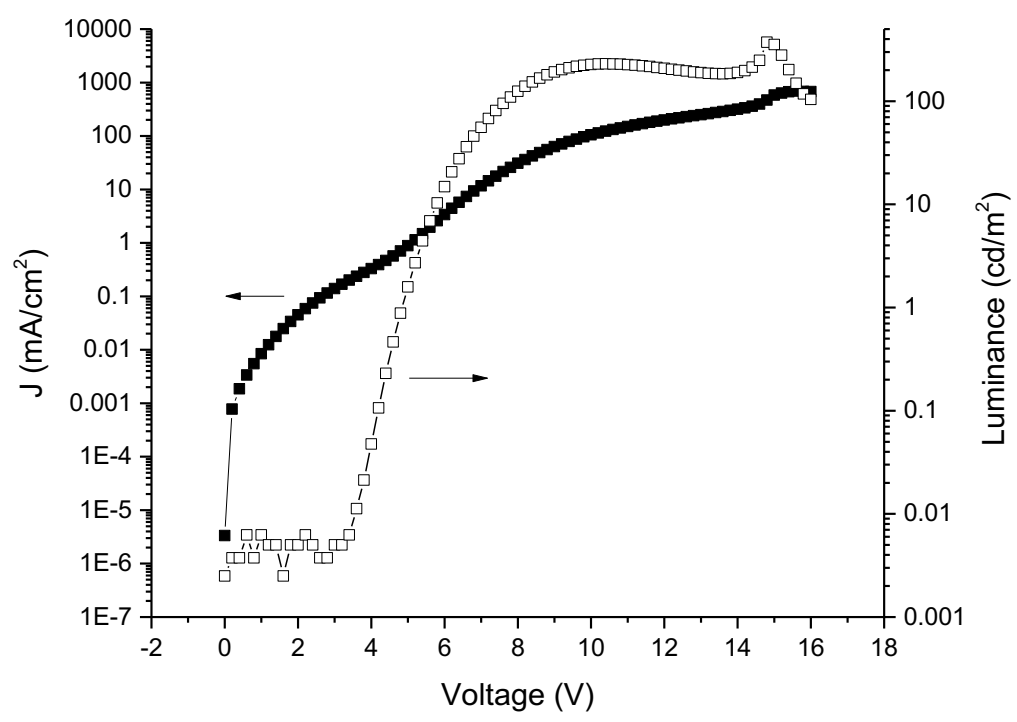


Figure S22 Efficiency of OLED device with 15 wt\% (-)-1 in OXD-7:PVK 70:30 matrix from matrix ratio screen.

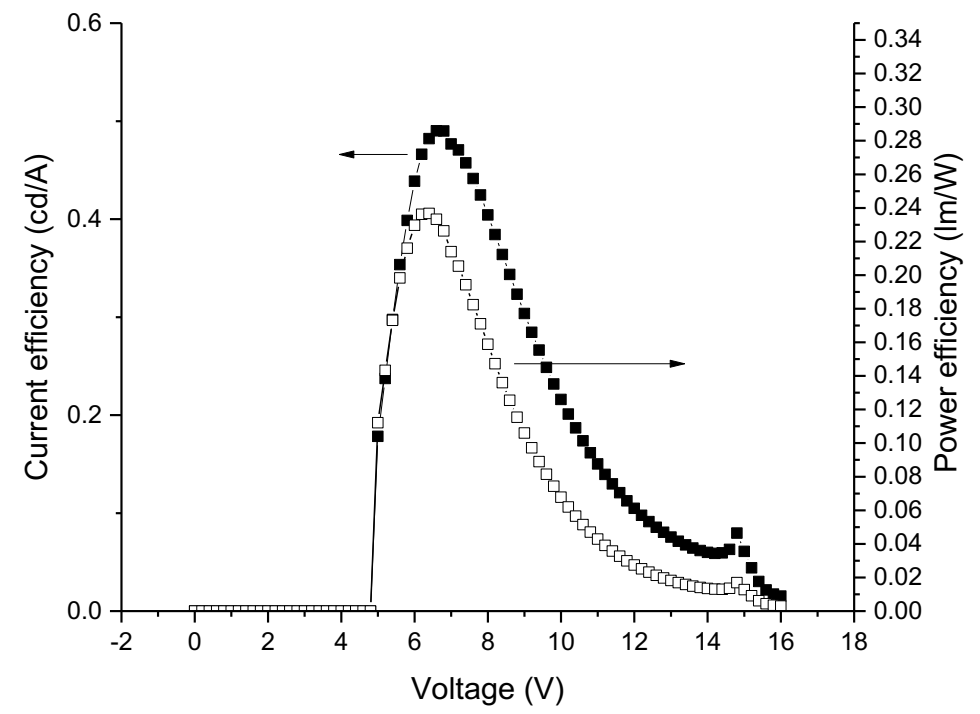

Figure S23 Current efficiency dependent on OXD-7:PVK ratio (OXD-7+PVK $=10 \mathrm{mg} / \mathrm{mL}$ in chloroform); 15 wt\% (-)-1.

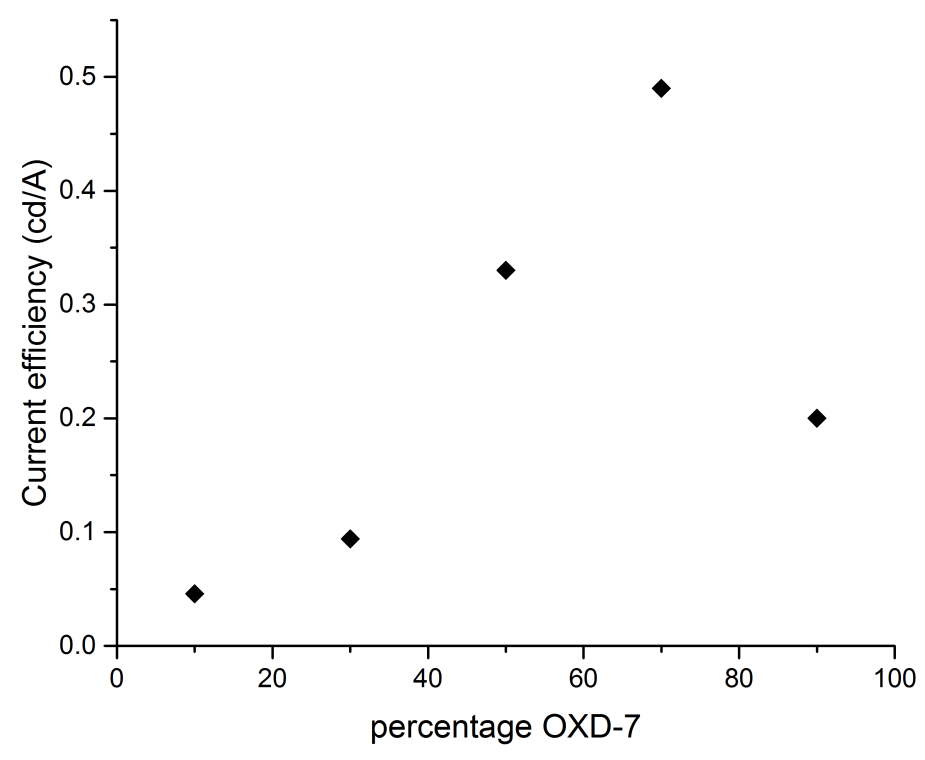


Figure S24 g-Factor dependent on OXD-7:PVK ratio (OXD-7+PVK $=10 \mathrm{mg} / \mathrm{mL}$ in chloroform); 15 wt\% (-)-1.

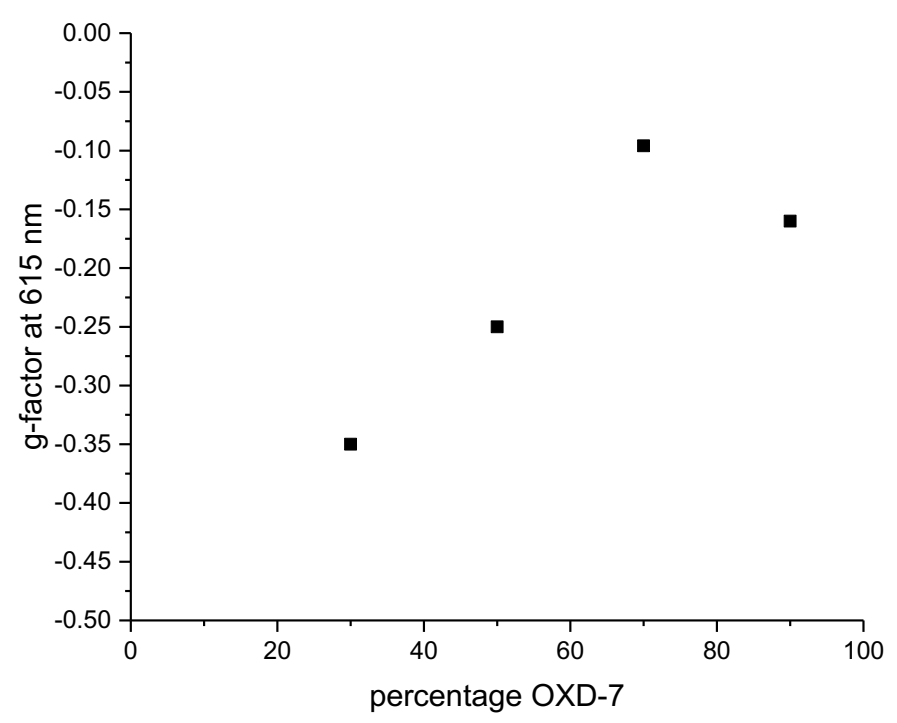

Devices with a OXD-7:PVK ratio of 10:90 were not bright enough to allow the measurement of CP-EL spectra.

Figure S25 Dependence of g-factor and power efficiency on Ca cathode thickness for 5 wt\% (-)-1, OXD-7:PVK 70:30.

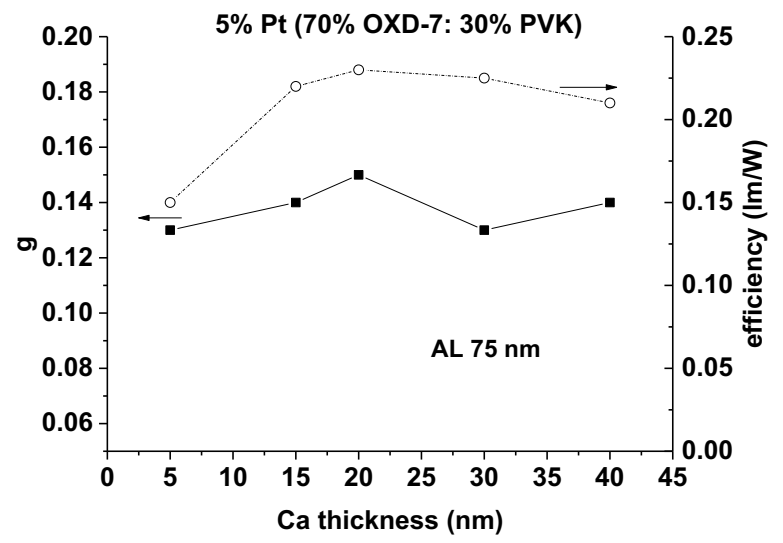


Figure S26 Dependence of g-factor and power efficiency on Al cathode thickness for 5 wt\% (-)-1, OXD-7:PVK 70:30.

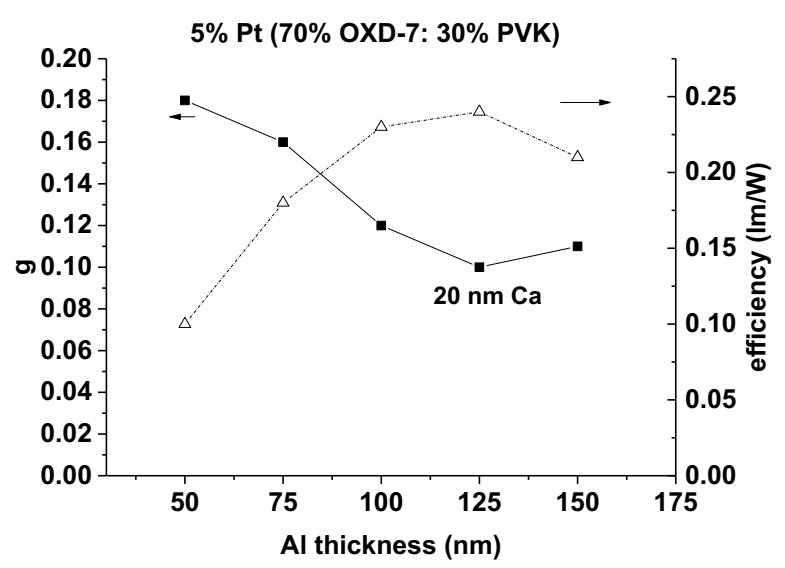

All tested Al layer thicknesses possess saturation level reflectance (approximately $90 \%$ ). ${ }^{13}$ It is unlikely that the increase in $\left|\mathrm{g}_{\mathrm{EL}}\right|$ is caused by a change in cathode reflectivity: ${ }^{3}$ the presence of the cathode does not degrade $\left|\mathrm{g}_{\mathrm{EL}}\right|$ compared to $\left|\mathrm{g}_{\mathrm{PL}}\right|$, which is measured on silica-mounted films (see Figure 2D and Figure $3 \mathrm{C}$ ). Instead, a possible explanation for the influence of cathode thickness on $\left|\mathrm{g}_{\mathrm{EL}}\right|$ could be a change in the carrier balance and recombination zone position.

Figure S27 J-V-L graph of OLED device with 15 wt\% (+)-1 in OXD-7:PVK 70:30 matrix.

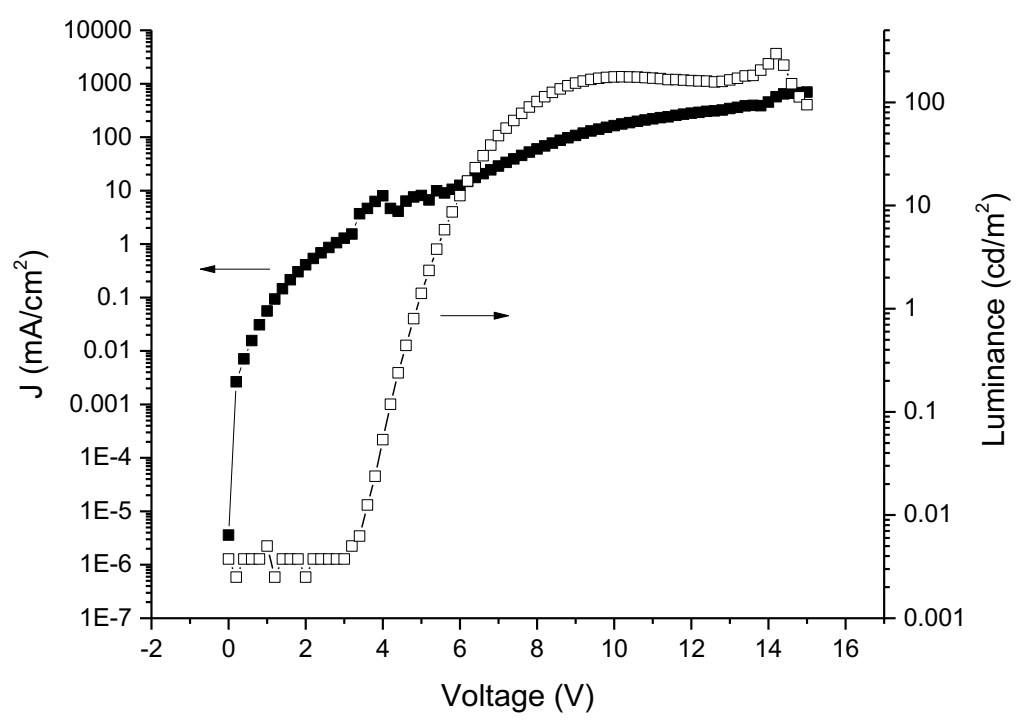


Figure S28 Efficiency of OLED device with 15 wt\% (+)-1 in OXD-7:PVK 70:30 matrix.

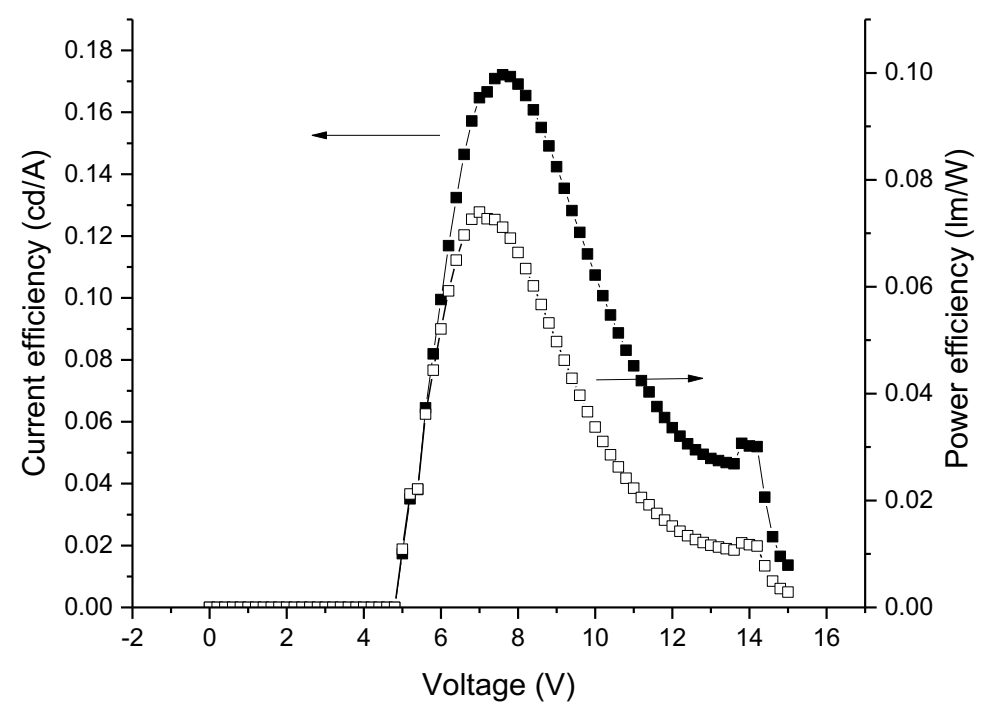

\section{Synthetic procedures}

\section{2-Methoxy-5-(pyridin-2-yl)benzaldehyde (S1)}

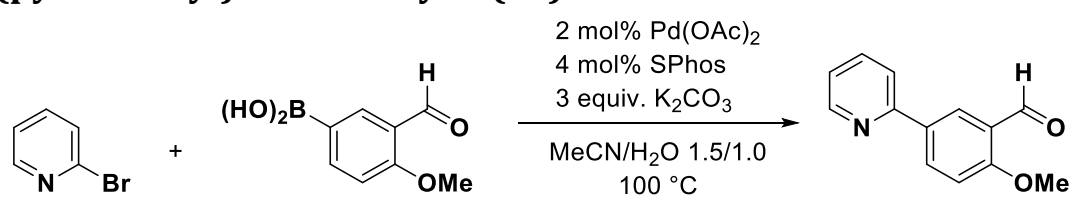

(3-Formyl-4-methoxyphenyl)boronic acid $(4.25 \mathrm{~g}, 23.6 \mathrm{mmol}, 1.50$ equiv.), palladium acetate (70.5 mg, $0.314 \mathrm{mmol}, 2.00 \mathrm{~mol} \%)$, SPhos $(258 \mathrm{mg}, 0.628 \mathrm{mmol}, 4.00 \mathrm{~mol} \%$ ) and potassium carbonate $(6.5 \mathrm{~g}, 47 \mathrm{mmol}, 3.0$ equiv.) were transferred into a $250 \mathrm{~mL}$ Young tube. The atmosphere was cycled between vacuum and nitrogen three times. Then, acetonitrile $\left(24 \mathrm{~mL}\right.$, deaerated by $\mathrm{N}_{2}$ sparging for $20 \mathrm{~min}$ ) and water ( $16 \mathrm{~mL}$, deaerated by $\mathrm{N}_{2}$ sparging for $20 \mathrm{~min}$ ) were added and the mixture heated to $100^{\circ} \mathrm{C}$ under a nitrogen atmosphere. After $1 \mathrm{~h}$, the generated carbon dioxide was vented from the Young tube. After a total reaction time of $16 \mathrm{~h}$, the mixture was allowed to cool to room temperature and the two phases were separated. The aqueous layer was extracted with DCM $(2 \times 15 \mathrm{~mL})$ and the combined organic layers diluted with DCM to a total volume of approximately 80 $\mathrm{mL}$. The product was extracted with concentrated hydrochloric acid $(3 \times 10 \mathrm{~mL})$. The combined aqueous layers were cooled to $0{ }^{\circ} \mathrm{C}$ and carefully basified $(\mathrm{pH}>14)$ with an aqueous $40 \mathrm{wt} \%$ sodium hydroxide solution. The product was extracted with DCM $(6 \times 20 \mathrm{~mL})$ until the organic layer showed no more UV absorption on a TLC plate. The combined organic layers were washed with brine $(2 \mathrm{x}$ $15 \mathrm{~mL}$ ) and dried over sodium sulphate, filtered and concentrated to afford the title compound as a beige powder ( $2.99 \mathrm{~g}, 14.0 \mathrm{mmol}, 89 \%)$.

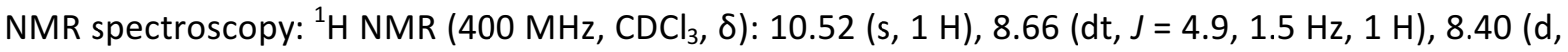
$J=2.4 \mathrm{~Hz}, 1 \mathrm{H}), 8.35(\mathrm{dd}, J=8.3,2.4 \mathrm{~Hz}, 1 \mathrm{H}), 7.73-7.77(\mathrm{~m}, 2 \mathrm{H}), 7.22(\mathrm{td}, J=5.0,3.7 \mathrm{~Hz}, 1 \mathrm{H}), 7.12$ $(\mathrm{d}, J=8.8 \mathrm{~Hz}, 1 \mathrm{H}), 4.00$ (s, $3 \mathrm{H}) .{ }^{13} \mathrm{C} \mathrm{NMR}\left(100 \mathrm{MHz} \mathrm{CDCl}_{3}, \delta\right): 189.8,162.5,156.0,149.8,137.0$, $134.6,132.2,127.0,124.9,122.2,120.1,112.3,56.1 . v_{\max } / \mathrm{cm}^{-1}$ (neat): $2878,1672,1582,1503,1466$, 
$1429,1397,1269,1170,1115,1018,908,777,648,519 . \mathrm{HRMS}-\mathrm{APCl}(\mathrm{m} / \mathrm{z})$ : calcd for $\mathrm{C}_{13} \mathrm{H}_{12} \mathrm{NO}_{2}[\mathrm{M}+$ $\mathrm{H}^{+}, 214.0863$; found, 214.0858 . 
Spectroscopic data

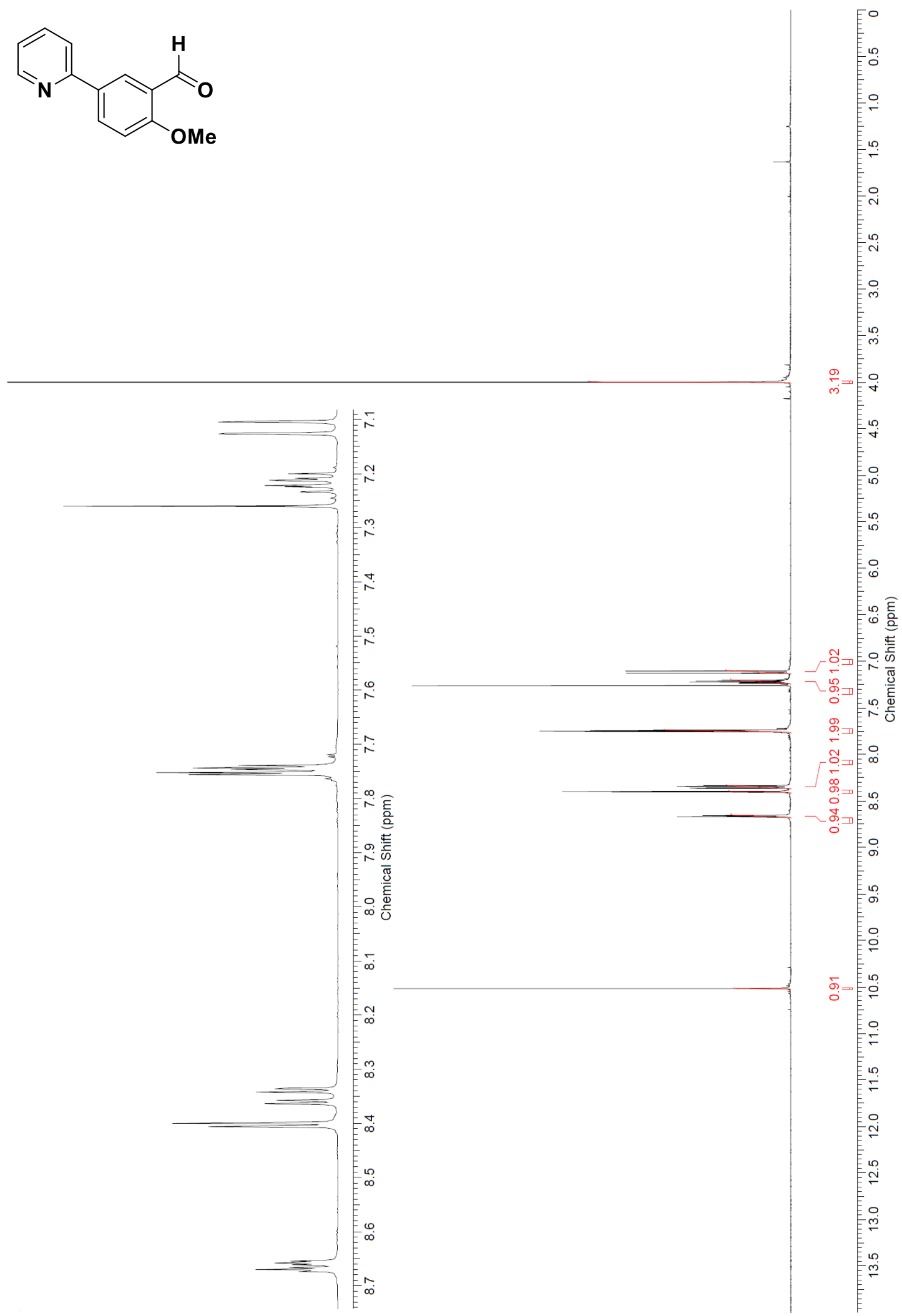

${ }^{1} \mathrm{H} \mathrm{NMR}\left(\mathrm{CDCl}_{3}, 23^{\circ} \mathrm{C}\right)$ of $\mathbf{S 1}$ 


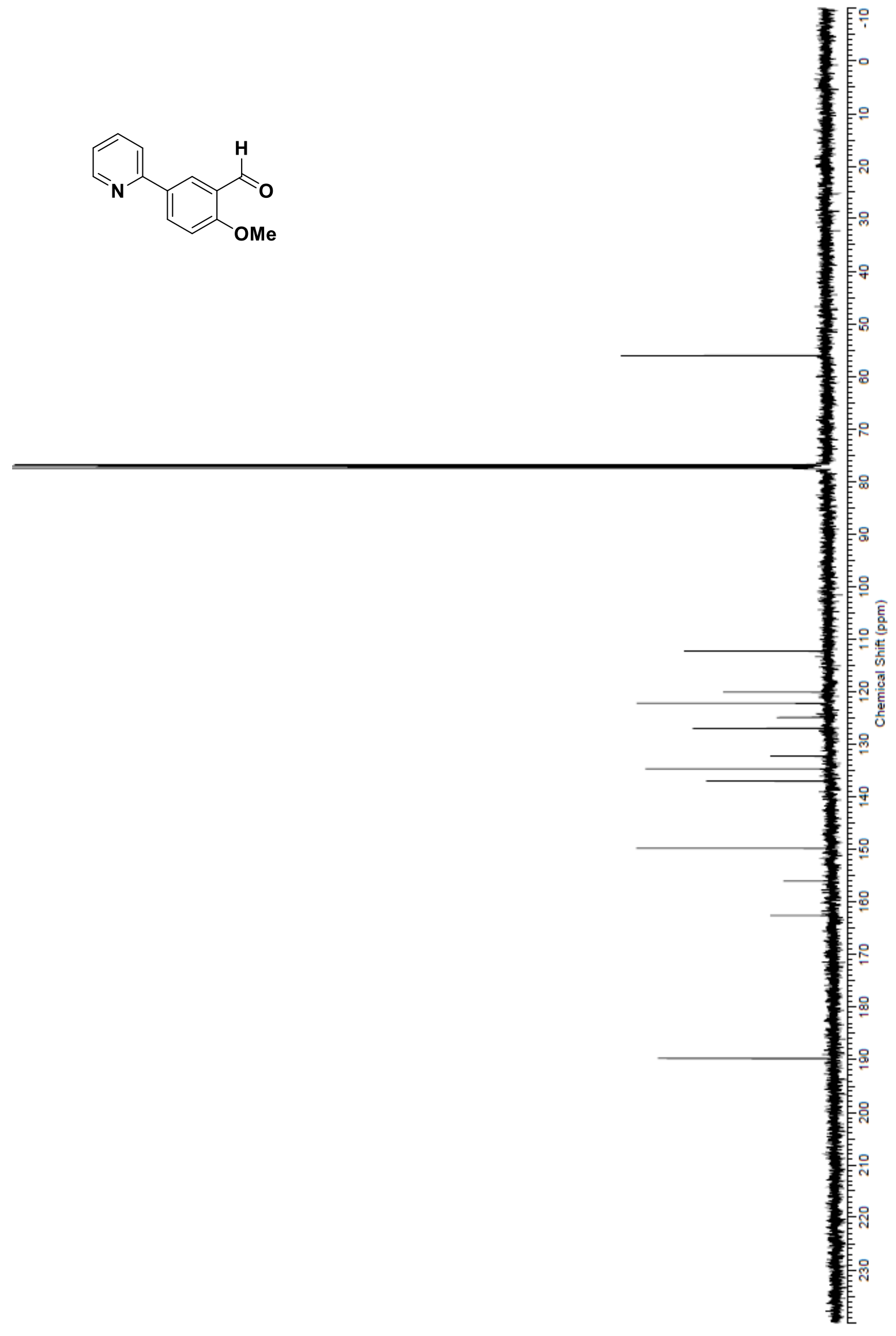

${ }^{13} \mathrm{C}$ NMR $\left(\mathrm{CDCl}_{3}, 23^{\circ} \mathrm{C}\right)$ of $\mathbf{S 1}$ 


\section{References}

(1) Yang, Y.; da Costa, R. C.; Smilgies, D.-M.; Campbell, A. J.; Fuchter, M. J. Adv. Mater. 2013, 25, 2624-2628.

(2) Geng, Y.; Trajkovska, A.; Culligan, S. W.; Ou, J. J.; Chen, H. M. P.; Katsis, D.; Chen, S. H. J. Am. Chem. Soc. 2003, 125, 14032-14038.

(3) Zinna, F.; Giovanella, U.; Di Bari, L. Adv. Mater. 2015, 27, 1791-1795.

(4) Li, T.-Y.; Jing, Y.-M.; Liu, X.; Zhao, Y.; Shi, L.; Tang, Z.; Zheng, Y.-X.; Zuo, J.-L. Sci. Rep. 2015, 5, 14912.

(5) Norel, L.; Rudolph, M.; Vanthuyne, N.; Williams, J. A. G.; Lescop, C.; Roussel, C.; Autschbach, J.; Crassous, J.; Réau, R. Angew. Chemie Int. Ed. 2010, 49, 99-102.

(6) Still, W. C.; Kahn, M.; Mitra, A. J. Org. Chem. 1978, 43, 2923-2925.

(7) Wang, C.; Jung, G.-Y.; Batsanov, A. S.; Bryce, M. R.; Petty, M. C. J. Mater. Chem. 2002, 12, 173-180.

(8) Fulmer, G. R.; Miller, A. J. M.; Sherden, N. H.; Gottlieb, H. E.; Nudelman, A.; Stoltz, B. M.; Bercaw, J. E.; Goldberg, K. I. Organometallics 2010, 29, 2176-2179.

(9) Brédas, J. L.; Silbey, R.; Boudreaux, D. S.; Chance, R. R. J. Am. Chem. Soc. 1983, 105, 65556559.

(10) D’Andrade, B. W.; Datta, S.; Forrest, S. R.; Djurovich, P.; Polikarpov, E.; Thompson, M. E. Org. Electron. 2005, 6, 11-20.

(11) Mabbott, G. A. J. Chem. Educ. 1983, 60, 697-702.

(12) Singh, R.; Unni, K. N. N.; Solanki, A.; Deepak. Opt. Mater. (Amst). 2012, 34, 716-723.

(13) Hass, G.; Waylonis, J. E. J. Opt. Soc. Am. 1961, 51, 719. 